DUCE, Mauricio. "La condena de inocentes en Chile: una aproximación empírica a partir de los resultados de los recursos de revisión acogidos por la Corte Suprema en el período 2007-2013".

Polít. crim. Vol. 10, № 19 (Julio 2015), Art. 6, pp. 159-191. [http://www.politicacriminal.cl/Vol_10/n_19/Vol10N19A6.pdf]

\title{
La condena de inocentes en Chile: una aproximación empírica a partir de los resultados de los recursos de revisión acogidos por la Corte Suprema en el período 2007-2013.
}

\section{The conviction of innocents in Chile: an empirical approximation from the results of wrongful conviction claims admitted by the Supreme Court during the 2007-2013 period.}

\author{
Mauricio Duce J. \\ Magíster en Ciencias Jurídicas (J.S.M) Universidad de Stanford, Profesor Titular de la \\ Facultad de Derecho Universidad Diego Portales \\ mauricio.duce@udp.cl
}

\section{Resumen}

El objetivo del trabajo es contribuir a mejorar el conocimiento disponible en materia de errores del sistema de justicia penal por medio de entregar información empírica obtenida a partir del análisis de los casos de condenas erróneas acreditados por la Corte Suprema al haber acogido un recurso de revisión en el contexto de funcionamiento del Código Procesal Penal acusatorio entre los años 2007-2013. La investigación analiza y presenta los principales aspectos contenidos en la base de datos de la Corte Suprema (470 casos) y en la lectura de todos los fallos de revisión acogidos en el período en estudio (44 casos) con el propósito de caracterizar los casos de acuerdo a tres tipos de variables: datos generales; aspectos del recurso de revisión acogidos; y, finalmente, causas que explican las condenas erróneas.

Palabras clave: Errores del sistema, condena de inocentes, recurso de revisión, causas.

\begin{abstract}
The objective of this paper is to improve the knowledge available in Chile regarding to miscarriages of justice by delivering empirical information obtained from cases of wrongful convictions exonerated by the Supreme Court in the context of the work of our adversarial system regulated in the Criminal Procedural Code between years 2007-2013. The research analyses and present the main aspects from the data base of the Supreme Court (470 cases) and the reading of all the decisions of wrongful convictions claims (recursos de revisión) admitted in the period (44 cases). The purpose is to depict those cases according three types of variables: general information; aspects of the wrongful convictions claims; and, causes that explain the wrongful convictions.
\end{abstract}

Keywords: Miscarriages of justice, wrongful convictions, wrongful conviction claim, causes. 
DUCE, Mauricio. "La condena de inocentes en Chile: una aproximación empírica a partir de los resultados de los recursos de revisión acogidos por la Corte Suprema en el período 2007-2013".

\section{Introducción*}

En el último tiempo se ha venido instalando una incipiente preocupación en nuestro país frente a la posibilidad que el sistema de justicia penal pueda cometer errores que perjudiquen a personas que no han cometido delitos $\mathrm{y}$, más específicamente, que se traduzcan en una condena a un inocente ${ }^{1}$. Se trata de un problema que ha sido puesto en debate en buena medida gracias al trabajo realizado por la Defensoría Penal Pública, quienes, a través de su Proyecto Inocentes, han dado a conocer diversos casos de personas que han sufrido las consecuencias de una persecución penal sin haber cometido los delitos imputados ${ }^{2}$. Junto con este trabajo, el tema ha comenzado poco a poco a ser objeto de preocupación de parte de la doctrina nacional, la que ha iniciado su estudio poniendo énfasis en identificar potenciales causas que podrían favorecer la producción de condenas y persecuciones penales erróneas en el país ${ }^{3}$.

No obstante este incipiente desarrollo de parte de la doctrina nacional, todavía se trata de un tema que ha sido objeto de poca investigación. Un área en donde hay particularmente un serio déficit de información es en el conocimiento empírico de nuestra realidad. Así, la información que disponemos en Chile acerca de la cantidad de casos en que se producen errores del sistema y condenas erróneas es casi nula. En esta línea, no existen investigaciones que de manera sistemática entreguen datos acerca del número total de condenas erróneas, ni tampoco trabajos que establezcan la probabilidad o porcentaje de casos en los que se podría condenar a inocentes. Por otra parte, no existe un registro completo de casos en donde se han producido errores graves del sistema o incluso de las

\footnotetext{
* Este trabajo ha sido elaborado en el contexto de preparación y luego ejecución de un proyecto Fondecyt Regular $\mathrm{n}^{\circ} 1150073$ denominado "Errores de la justicia penal: investigación empírica y dogmática sobre sus causas en nuestro país y recomendaciones para evitarlos". El período de desarrollo del proyecto cubre los años 2015-2018 y el autor tiene la calidad de investigador responsable en el mismo.

${ }^{1}$ Un ejemplo de como esta preocupación ha tenido un cierto impacto en medios de comunicación puede verse en GUADARRAMA, Cecilia, "Encarcelados por Error”, Revista Sábado, no 801 (2014), pp. 16-19.

${ }^{2}$ Se trata de un proyecto que existe formalmente desde el año 2013. En agosto de ese año, la Defensoría Penal Pública realizó la presentación pública del Proyecto Inocentes y su página web. Según lo que señala ésta, el proyecto pretende sensibilizar a la sociedad acerca de la posibilidad que el sistema de justicia penal cometa errores por medio de la identificación y documentación de casos en que ello ha ocurrido. De esta forma se “....busca imponer nuevos desafíos para mejorar ciertas prácticas, hábitos y rutinas de trabajo de los principales actores del sistema de justicia”. El proyecto también “...busca permitir que las personas injustamente involucradas en estos casos cuenten con un lugar de reconocimiento permanente y público sobre su inocencia". Véase http://www.proyectoinocentes.cl (última visita 23 de marzo de 2015).

${ }^{3}$ En el año 2013 se publicaron los primeros trabajos en nuestro país que analizan el problema de las condenas erróneas desde una perspectiva general en el funcionamiento del sistema acusatorio y en todos ellos el claro énfasis se encuentra en el análisis de las causas que podrían generar estos errores. Véase CASTILLO, Ignacio, "Enjuiciando al proceso penal chileno desde el inocentrismo (algunos apuntes sobre la necesidad de tomarse en serio a los inocentes)", Polít. crim. Vol. 8, nº 15 (Julio 2013), Art. 7, pp. 249-313; DUCE, Mauricio. "¿Debiéramos preocuparnos de la condena de inocentes en Chile? Antecedentes comparados y locales para el debate", Revista Ius et Praxis, año 19 no 1 (2013), pp. 77-138; y, DUCE, Mauricio, "Errores del sistema y condena de inocentes: nuevos desafíos para nuestra justicia penal acusatoria", en: DECAP, Mauricio et. al, El modelo adversarial en Chile, Santiago: Legalpublishing, 2013, pp. 1-65.
} 
Polít. crim. Vol. 10, № 19 (Julio 2015), Art. 6, pp. 159-191.

[http://www.politicacriminal.cl/Vol_10/n_19/Vol10N19A6.pdf]

personas que han sido exoneradas luego de una condena errónea ${ }^{4}$. La falta de esta información ha impedido saber con exactitud la frecuencia y magnitud del problema.

Se trata de una carencia muy significativa. Como lo demuestra la experiencia comparada, la falta de información empírica no sólo impide conocer la magnitud de un problema muy relevante de funcionamiento de un sistema de justicia penal, sino que incluso permite el desarrollo de posturas de negación de su existencia o, al menos, de minimización del mismo, que dificultan que éste se instale como un catalizador de cambios y mejoras que son necesarias ${ }^{5}$.

En este contexto, el presente trabajo pretende contribuir a aumentar el conocimiento disponible en el área por medio de entregar información de los casos de condenas erróneas acreditados por la Corte Suprema al haber acogido un recurso o acción de revisión ${ }^{6}$. La investigación se focalizará en los casos presentados y resueltos en el contexto de funcionamiento del Código Procesal Penal acusatorio (en adelante el CPP), dejando de lado los que se refieren al sistema inquisitivo previo ${ }^{7}$. Específicamente, cubriré los casos de revisión presentados entre los años 2007 y 2013. Como se puede apreciar, el trabajo se detiene en el análisis de una base relativamente acotada de casos, pero en donde es claro se ha producido un error grave ya que se ha condenado a alguien de manera equivocada. De esta manera, se pretende tener una primera aproximación con respaldo empírico acerca de la magnitud del problema de las condenas erróneas en nuestro país y del tipo de casos en donde éste se ha presentado.

\footnotetext{
${ }^{4}$ Un matiz sobre esta afirmación. Como ya señalé, una función central del Proyecto Inocentes de la Defensoría Penal Pública es identificar y registrar casos de errores del sistema. Con todo, se trata de un proyecto que no tiene como propósito central el registro sistemático y completo de todas las condenas erróneas generadas en nuestro sistema procesal penal acusatorio. Por ejemplo, a inicios del mes de marzo de 2015 la página web del proyecto aún no incluía los casos en donde la Corte Suprema ha revocado sentencias condenatorias como producto de conceder recursos de revisión. Hasta el momento en que se escribió este trabajo sólo uno de los 40 casos registrados incluía a una persona condenada que luego fue exonerada por esta vía.

${ }^{5}$ La historia del movimiento "inocentrista" en los Estados Unidos da cuenta que es común la postura de negación del problema cuando se inicia su debate. Esto se realiza en dos niveles: el macro en el cual se niega derechamente la existencia del problema de condenas de inocentes; y, el micro, en el cual se discute la inocencia de las personas exoneradas en casos particulares. FINDLEY, Keith, "Defining innocence", Alabama Law Review, vol. 74.3 (2011), pp. 1157-1208, p. 1158.

${ }^{6}$ Se trata de un mecanismo que permite rever sentencias condenatorias firmes en hipótesis reguladas en el artículo 473 del Código Procesal Penal. Una visión panorámica de este mecanismo como también un análisis de su práctica (focalizado a una de sus causales) puede verse en FERNÁNDEZ, José Manuel y OLAVARRÍA, Malva, "Teoría y Práctica de la Acción de Revisión en el Nuevo Código Procesal Penal, Causal letra d) del artículo 473”, Revista Ius et Praxis, Año 15, no 2 (2009), pp. 215-255. Una visión más general puede verse en HORVITZ, María Inés y LÓPEZ, Julián, Derecho procesal penal chileno, Tomo II, Santiago: Editorial Jurídica de Chile, 2004, 659 pp., pp. 447-457.

${ }^{7}$ En este mismo período la Corte Suprema ha acogido varios recursos de revisión que provienen de condenas generadas en el sistema inquisitivo que quedarán fuera. Por ejemplo, véase caso rol no 2827-2011 (de julio de 2011), en el que la Corte exoneró a Rodrigo Saavedra quien originalmente había sido condenado a 15 años de privación de libertad por violación de su hija de nueve años y quien estuvo cerca de 10 años preso antes de acogerse el recurso de revisión. Información del caso aparecida en la prensa puede verse en http://www.emol.com/noticias/nacional/2013/09/26/621626/colectivero-falsamente-condenado-por-violacionle-dijo-al-ejecutivo-que-volvera-a-ver-a-ver-a-sus-ninas-finde.html (última visita el 23 de marzo de 2015).
} 
DUCE, Mauricio. "La condena de inocentes en Chile: una aproximación empírica a partir de los resultados de los recursos de revisión acogidos por la Corte Suprema en el período 2007-2013".

Para cumplir el objetivo planteado, el trabajo se dividirá en dos capítulos además de esta introducción. En el primero de ellos se abordarán de manera breve algunos aspectos generales sobre el objeto de análisis que permitirán precisar mejor los alcances de esta investigación. El segundo capítulo presentará los resultados obtenidos en el análisis de la base de datos de la Corte Suprema en materia de recursos de revisión en el período 20072013 y de la lectura de los fallos en que éstos fueron acogidos. Así, se avanzará en el procesamiento de los datos básicos realizando un esfuerzo por caracterizar a los casos en donde el recurso de revisión ha sido acogido de acuerdo a tres tipos de variables: datos generales de los casos; aspectos del recurso de revisión acogidos; y, finalmente, causas que explican las condenas erróneas. Cabe señalar que la investigación pone énfasis en al presentación de datos e información y no en el análisis profundo de los casos, ya que eso supone una metodología diferente de trabajo a la escogida ${ }^{8}$. Finalmente, el trabajo concluirá con una breve sección destinada a presentar algunas reflexiones finales sobre los principales hallazgos.

\section{Aspectos generales sobre los errores del sistema y las condenas de inocentes.}

Tal vez si una primera aclaración que es necesario hacer se refiere al objeto de estudio de esta investigación. En la introducción de este trabajo he hablado indistintamente de errores del sistema y de condena erróneas, aún cuando es necesario precisar que se trata de conceptos diferentes. Cuando se habla de errores del sistema se está haciendo referencia a una categoría mucho más amplia de problemas de funcionamiento del sistema de justicia criminal en las que se pueden incluir los casos en donde se condena erróneamente a un inocente, pero también muchos otros en los que se presentan problemas graves sin que incluso exista una condena. En esta misma dirección, parte importante de la literatura anglosajona suele utilizar la etiqueta de "miscarriages of justice" (cuya traducción podría ser "extravíos de la justicia") para referirse al tema, enfatizando de esta manera una concepción amplia del mismo. Así, por ejemplo, Brian Forst señala que la condena de inocentes es sólo una parte del problema de los "miscarriages of justice" que también incluirían situaciones como la absolución de culpables, el no perseguir delitos que efectivamente han sido cometidos, el arrestar y mantener presos durante el proceso a personas inocentes sin que luego sean condenadas, entre otras?

No obstante la relevancia de todo este tipo de errores del sistema entendidos de una manera amplia, en este trabajo me detendré sólo en el problema de las condenas erróneas o de personas inocentes ${ }^{10}$. Aún cuando se trata de un universo más acotado, no es una categoría

\footnotetext{
${ }^{8}$ El análisis en profundidad de los casos supondría un método de "estudio de casos" que requiere, entre otras cuestiones, no sólo el análisis de las sentencias de revisión sino de todos los documentos del caso, incluyendo sentencias de instancia y tribunales superiores, carpeta investigativa del fiscal, audios de las audiencias, etc. En otros trabajos avanzaré en esta dirección.

${ }^{9}$ FORST, Brian, "Wrongful convictions in a world of miscarriages of justice", en: HUFF, Ronald y KILLIAS, Martin (Eds.), Wrongful conviction and miscarriages of justice: causes and remedies in North American and European criminal justice systems. New York: Routledge, 2013, pp. 15-43.

${ }^{10}$ De acuerdo a Forst, si bien muchos de los casos de errores del sistema no obedecen al mismo problema que los de las condenas de inocentes, tratándose de las personas que han sufrido privaciones de libertad sin
} 
Polít. crim. Vol. 10, № 19 (Julio 2015), Art. 6, pp. 159-191.

[http://www.politicacriminal.cl/Vol_10/n_19/Vol10N19A6.pdf]

completamente pacífica en el debate doctrinal. Así, hay quienes plantean que detrás de la idea de "inocencia" coexisten distintas situaciones que son muy diversas. En nuestro país, Castillo ha presentado el problema distinguiendo entre personas "fácticamente" y "normativamente" inocentes, siguiendo así la discusión de la literatura comparada. Sostiene que el caso que debiera generar una preocupación especial por su gravedad es el de las personas "fácticamente" inocentes, es decir, quienes no han cometido el delito que se les imputa (ya sea debido a que un tercero lo cometió o el delito no existió). Se trataría de un caso distinto al de los "normativamente" inocentes, es decir, aquellos que han cometido realmente el delito pero han sido declarados inocentes por razones normativas (por ejemplo por la prescripción) ${ }^{11}$.

No es el objetivo de este trabajo entrar en distinciones conceptuales profundas en el tema, ya que muchas de ellas presentan problemas importantes y su esclarecimiento requeriría de varios matices que harían perder el foco de esta investigación ${ }^{12}$. En buena medida es posible ahorrarme ese debate ya que este trabajo se detiene en aquellos casos de condenas erróneas que me parece son los menos discutibles en nuestro sistema jurídico: aquellos en que la Corte Suprema se ha pronunciado específicamente señalando la inocencia de los condenados.

Es necesario aclarar este punto. Según plantean Fernández y Olavarría, una vez que ha sido declarado admisible un recurso de revisión, la Corte Suprema tiene tres posibilidades: (i) dar por fehacientemente acreditada la inocencia del condenado, (ii) entender que la inocencia no se ha acreditado fehacientemente, o (iii) concluir que la inocencia del condenado no fue probada ${ }^{13}$. Por su parte, el artículo 478 inciso segundo del CPP establece que si de los antecedentes presentados en el recurso queda fehacientemente acreditada la inocencia del condenado, la Corte Suprema puede dictar sentencia de reemplazo. En consecuencia, en caso que esto no ocurra, la Corte podría simplemente acoger una revisión y ordenar la nulidad de la sentencia, permitiendo así la realización de un nuevo juicio. Como se puede apreciar, conceptualmente existiría en nuestro país la posibilidad de revisiones acogidas sin inocencia acreditada. En la práctica esto no ocurre. El resultado del análisis que realizan Fernández y Olavarría concluye que en todos los casos cubiertos en su investigación en los que la Corte acogió el recurso, se lo hizo dando por fehacientemente acreditada la inocencia del recurrente ${ }^{14}$. Algo similar ocurre con los casos cubiertos en esta investigación. En todos ellos, la Corte Suprema acogió un recurso y se pronunció sobre la inocencia del condenado originalmente, anulando la sentencia y dictando sentencia de reemplazo de acuerdo a lo dispuesto por el artículo 478 inciso segundo del CPP.

\footnotetext{
sentencia, las causas que los generan son similares y sus efectos igualmente devastadores. FORST, "Wrongful", cit. nota no 9, p. 17.

${ }^{11}$ CASTILLO, "Enjuiciando", cit. nota no 3, pp. 252-253.

${ }^{12}$ Se trata de un tema que admite mucho más matices y debates tal como se ha dado en los Estados Unidos. Véase FINDLEY, "Defining”, cit. nota no 5, pp. 1157-1208.

${ }^{13}$ FERNÁNDEZ/OLAVARRÍA, "Teoría”, cit. nota nº 6, p. 238.

${ }^{14}$ Se trata de una investigación que analizó todos los fallos de revisión de la Corte Suprema en el período comprendido entre el 2 de enero de 2007 y el 30 de abril de 2009 (229 acciones revisión). Véase FERNÁNDEZ/OLAVARRÍA, "Teoría”, cit. nota nº 6, pp. 252-254.
} 
DUCE, Mauricio. "La condena de inocentes en Chile: una aproximación empírica a partir de los resultados de los recursos de revisión acogidos por la Corte Suprema en el período 2007-2013".

En consecuencia, esta investigación recae en casos de extrema gravedad para nuestro ordenamiento jurídico en los que me parece sería absurdo discutir su relevancia. Ahora bien, trabajar con este grupo de casos presenta un problema que es necesario destacar. Ellos abarcan sólo de una pequeña porción de los casos en que es posible pensar el sistema incurre en errores importantes con consecuencias graves para la persona objeto de investigación. Por de pronto, el foco en estos caso deja fuera todo tipo de hipótesis en donde los errores se producen sin condena ${ }^{15}$. Además, quedan fuera los casos en que se puede haber condenado a una persona erróneamente pero ella no ha podido ejercer una acción de este tipo. En esta misma dirección, existe un acuerdo importante en la literatura comparada de entender que los casos de exoneración formal son sólo la punta del iceberg de un problema mucho mayor. Esto debido a que existen muchos casos de condenas erróneas que no llegan a estas instancias formales por diversos motivos o barreras de acceso $^{16}$.

La situación descrita en el ámbito comparado parece coincidir claramente con el caso chileno. La regulación legal del recurso de revisión ha sido históricamente bastante restrictiva. Así, el CPP establece hipótesis muy restringidas para su procedencia ${ }^{17}$ que, sumados a una interpretación estricta y formalista que se ha hecho tradicionalmente de las mismas, hace que un porcentaje bajo de los casos que se presentan tenga la posibilidad de obtener una decisión favorable ${ }^{18}$. De esta forma, es posible pensar que algunos de los casos

\footnotetext{
${ }^{15}$ Por ejemplo, la Defensoría Penal Pública ha venido llamando la atención desde hace algunos años sobre la situación de personas que han sido absueltas pero han estado presas en prisión preventiva, en algunos casos por largos períodos (todos más de 15 días). Así, entre los años 2008 y 2012 esa cifra se habría incrementado anualmente desde 367 a 746 absueltos por año, es decir, un 103\%. Véase DEFENSORÍA PENAL PÚBLICA, Informe Estadístico Anual 2012, pp. 23, disponible en http://www.dpp.cl/resources/upload/files/documento/9a4c122934927b0ee2c37842994663e5.pdf (última visita el 23 de marzo de 2015). Por otra parte, el Proyecto Inocentes al que ya he hecho referencia, a noviembre de 2014 ha documentado 40 casos de errores del sistema, dentro de los cuáles sólo uno ha sido objeto de sentencia condenatorio que luego dio pié a un recurso de revisión que fue acogidos (Caso de Julio Robles rol $\mathrm{n}^{\circ}$ 11.109-2013). Véase http://www.proyectoinocentes.cl/casos/listado (última visita el 23 de marzo de 2015). ${ }^{16}$ FINDLEY, Keith, "Adversarial inquisitions: rethinking the search for the truth", New York Law School Law Review, Vol. 56 (2011-2012), pp. 912-941, p. 918.

${ }^{17}$ En esta dirección Horvitz y López señalan "Como se puede apreciar, las causales que fundamentan la revisión de las sentencias firmes constituyen casos extremos en que resulta evidente que la legitimidad de la sentencia que impone una sanción penal se encuentra en crisis..." HORVITZ/LÓPEZ, Derecho procesal penal chileno, cit. nota $\mathrm{n}^{\circ} 6$, p. 451 (el subrayado es del autor).

${ }^{18} \mathrm{Al}$ hablar de interpretación estricta y formalista me refiero a una que reduce el alcance de las causales de revisión al tenor más literal de las mismas, sin hacer un esfuerzo por adaptar sus alcances tomando en cuenta consideraciones de orden teleológico y contextuales. Todo indica que este tipo interpretación de esta acción proviene de la jurisprudencia desarrollada por la Corte Suprema a las normas que regían la materia en el Código de Procedimiento Penal anterior. Cabe señalar que la regulación de la hipótesis central prevista en el artículo 657 de este Código se mantuvo en lo central idéntica a la del actual artículo 473. La jurisprudencia desarrollada en el contexto de vigencia del sistema inquisitivo puede revisarse en LIBEDINSKY, Marcos (redactor), Repertorio de Legislación y Jurisprudencia Chilenas Código de Procedimiento Penal, Tomo III. Santiago: Editorial Jurídica de Chile, 1983, 454 pp., pp. 397-405. Sobre el mismo punto Castillo concuerda que la Corte Suprema ha tenido una aproximación "restrictiva y excepcional". CASTILLO, "Enjuiciando", cit. nota $\mathrm{n}^{\circ} 3$, p. 254. Una visión crítica del recurso en la actualidad en cuanto a servir de herramienta idónea para proteger a inocentes puede ver en MARDONES, Fernando, "Guardar silencio: El Recurso de revisión, una mezquina protección al inocente”, Revista 93, No 6 (2011), pp. 45-47.
} 
Polít. crim. Vol. 10, № 19 (Julio 2015), Art. 6, pp. 159-191.

[http://www.politicacriminal.cl/Vol_10/n_19/Vol10N19A6.pdf]

que se presentan ante la Corte podrían ser condenas erróneas, pero ellos son filtrados previamente producto de las exigencias estrictas de procedencia de este mecanismo. La información empírica disponible tiende a mostrar este comportamiento. Así, el estudio que analizó todos los fallos de revisión de la Corte Suprema en el período comprendido entre el 2 de enero de 2007 y el 30 de abril de 2009 indica que de las 229 acciones presentadas, la gran mayoría fue rechazada de plano, es decir, casi sin fundamentos. En efecto, un 89,1\% de los recursos fueron desechados en resoluciones que no excedieron las 596 palabras ${ }^{19}$. En esta investigación revisé la base de datos de la Corte Suprema en materia de recursos o acciones de revisión en el período cubierto entre los años 2007 a 2013 y esta cifra se mantiene en márgenes bastante parecidos ${ }^{20}$. Así, del total de 470 recursos presentados en el período se puede apreciar como en un $81,27 \%$ (382 casos) la acción es "desechada de plano" $"$.

Este comportamiento estricto y formalista de la Corte no sólo podría estar dejando casos de condenas erróneas sin esclarecerse por problemas de admisibilidad o formales, sino además generar un fuerte desincentivo a personas condenadas para utilizar este mecanismo. A esto habría que sumar los casos en que se condena a un inocente y que no son objeto de recurso de revisión por la existencia de diversas dificultades y barreras de acceso que emanan de la falta de representación legal de los condenados, la escasa información que disponen sobre este mecanismo, la inexistencia de evidencia exculpatoria nueva, entre otras. En consecuencia, es razonable pensar que la cifra negra de condenas de inocentes es mucho mayor a los casos que son acogidos por la Corte Suprema.

Teniendo presente entonces que los casos en análisis no pretenden cubrir todo el universo de condenas de inocentes y, por cierto, el de errores del sistema, en la próxima sección me dedicaré a presentar la información que arroja los casos en que la Corte Suprema ha acogido recursos de revisión en el período 2007-2013.

\section{Análisis de los recursos de revisión acogidos por la Corte Suprema en el período 2007-2013.}

A partir de la información contenida en la base de datos que la Corte Suprema me entregó en materia de recursos o acciones de revisión en el período cubierto entre los años 2007 y 2013 he podido identificar y luego revisar las sentencias en la que se acogieron los

\footnotetext{
${ }^{19}$ FERNÁNDEZ/OLAVARRÍA, “Teoría”, cit. nota $\mathrm{n}^{\circ}$ 6, pp. 247-248. Cabe destacar que no existe otra investigación empírica en el país que entregue una información diversa a la de este estudio y los datos que he levantado en mi investigación. En consecuencia, explicaciones alternativas a estos hallazgos son sólo especulaciones con poco soporte en la realidad.

${ }^{20}$ La Dirección de Estudios, Análisis y Evaluación de la Corte Suprema me proporcionó una plantilla Excel con el listado completo de recursos en el período a través de envío electrónico el día 14 de julio de 2014. Dicho documento está en formato electrónico en poder del autor. Agradezco a Eduardo Alcaíno, coordinador del Programa de Reformas Procesales y Litigación de la Facultad de Derecho de la Universidad Diego Portales, quien contactó a la unidad y obtuvo los datos respectivos.

${ }^{21}$ A ello hay que agregar que en un $1,9 \%$ (9) la Corte rechazó por la causal "téngase por no presentado"; en un $0,4 \%$ fue desistido (2) y el mismo porcentaje fue declarado inadmisible. Sólo en un 4,25\% del total de acciones presentadas (20) la Corte Suprema rachaza el recurso por razones de fondo. El porcentaje de casos en que el recurso fue acogido será revisado en la próxima sección en detalle.
} 
DUCE, Mauricio. "La condena de inocentes en Chile: una aproximación empírica a partir de los resultados de los recursos de revisión acogidos por la Corte Suprema en el período 2007-2013".

recursos. El objetivo de esta sección será presentar los resultados de ese trabajo. Antes de iniciar esta tarea es necesario hacer algunas aclaraciones de temas básicos.

En primer lugar, como ya señalé, el análisis sólo considerará los casos de revisión que se han producido en el contexto de funcionamiento de nuestro sistema penal acusatorio. En segundo término, una explicación respecto al período considerado. Si bien el año 2006 es el primero en el que el sistema procesal acusatorio estuvo vigente en todo el país, debido a que los recursos de revisión se hacen procedentes una vez que existen sentencias condenatorias ejecutoriadas, es probable que sólo a partir del año 2007 se refleje en realidad el flujo regular en el ejercicio de este tipo de acciones. Por eso que considerar años previos podría llevar a generar algunas distorsiones acerca del funcionamiento del sistema. Por otra parte, las estadísticas que publica la Corporación Administrativa del Poder Judicial en la materia sólo distinguen los ingresos de los casos de sistema inquisitivo antiguo y el proceso acusatorio a partir del año 2007, lo que hace más fácil -sólo a partir de ese añodiscriminar bien los $\operatorname{casos}^{22}$. Finalmente, debo aclarar que los años de los casos hacen referencia al ingreso del recurso de revisión y no al año de resolución del mismo. Hay varios casos en que el ingreso corresponde a un año y la resolución al siguiente. Me ha parecido más ordenado mantener el año de presentación del recurso como criterio organizador para los efectos de este trabajo.

Con estas aclaraciones, la tabla $\mathrm{n}^{\mathrm{o}} 1$ contiene un resumen del total de acciones de revisión presentadas y de las acogidas en el período en estudio.

Tabla $\mathrm{n}^{\circ} 1$

Recursos de revisión ingresados y acogidos años 2007-2013

Fuente: Elaboración propia a partir de datos del Poder Judicial

\begin{tabular}{|c|c|c|c|}
\hline Año & Ingresos & Acogidos & \% \\
\hline 2007 & 32 & 3 & $9,37 \%$ \\
\hline 2008 & 61 & 6 & $9,83 \%$ \\
\hline 2009 & 77 & 5 & $6,49 \%$ \\
\hline 2010 & 85 & 11 & $12,94 \%$ \\
\hline 2011 & 88 & 5 & $5,68 \%$ \\
\hline 2012 & 58 & 11 & $18,96 \%$ \\
\hline 2013 & 69 & 3 & $4,34 \%$ \\
\hline Total & $\mathbf{4 7 0}$ & $\mathbf{4 4}$ & $\mathbf{9 , 3 6} \%$ \\
\hline
\end{tabular}

Según se puede apreciar, la estadística da cuenta de un flujo bastante importante de casos anuales que adquiere un número significativo a partir del año 2008, lo que probablemente

\footnotetext{
22 Véase CORPORACIÓN ADMINISTRATIVA DEL PODER JUDICIAL, Memoria Anual de la Corporación Administrativa del Poder Judicial 2007, pp. 38-39 disponible en: http://www.pjud.cl/documents/10179/103881/memoria_2007.pdf/ac86f791-4ac7-4568-832c-cd623c7674a7 (última visita el 10 de abril de 2015).
} 
Polít. crim. Vol. 10, № 19 (Julio 2015), Art. 6, pp. 159-191.

[http://www.politicacriminal.cl/Vol_10/n_19/Vol10N19A6.pdf]

muestra que hay un rezago entre la vigencia completa del sistema en todo el país y el uso de esta acción tal como mencionaba previamente.

Las cifras muestran que en un período de siete años se llega a un total de 470 recursos presentados. Esto da un promedio anual aproximado de 67 recursos. La tabla permite ver también que entre los años 2009 y 2011 se produjeron la mayor cantidad de ingresos anuales, aún cuando debido a la variabilidad del período no es posible concluir respecto a alguna tendencia clara a futuro.

La tabla muestra también que existe un número importante de recursos acogidos, $44^{23}$, que constituyen un no despreciable $9,36 \%$ del total de recursos presentados ${ }^{24}$. Se trata de una cifra que supera de manera importante el número de casos de revisiones acogidas que se conocían en estudios previos ${ }^{25}$. Esto nos muestra que el problema de condena de inocentes en nuestro país no sería para nada una "rareza" o, desde otro punto de vista, que se presenta con una frecuencia que debiera generar más atención de parte de los operadores del sistema y de la doctrina. La tabla permite identificar también que la variación de revisiones acogidas en números absolutos y porcentajes del total de ingresos es alta, sin que exista una tendencia clara de aumento o disminución a lo largo de los años. Así, por ejemplo, el año 2013 sólo hay tres revisiones acogidas y que representan el 4,34\% de los ingresos. El año previo, en cambio, se acogen 11 revisiones que representan prácticamente el $19 \%$ del total de ingresos. Fenómenos similares ocurren los años 2011 y 2010. Esto dificulta la capacidad de predecir con precisión el comportamiento a futuro en la materia.

En lo que sigue, aporto algunos datos de los casos objeto de estudio de manera que el lector pueda tener una caracterización básica de que tratan los mismos. Para estos efectos organizaré la presentación de la información en tres categorías. En la primera, presentaré información general de los casos en temas tales como el tipo y número de condenados erróneos, los delitos por los cuáles se les condenó, el tipo de pena originalmente impuesta, los tipos de procedimiento en donde dichas condenas fueron generadas y la distribución regional de los casos. En la segunda sección, presentaré datos vinculados a las acciones de revisión objeto de análisis, incluyendo quien las interpuso y la causal acogida por la Corte Suprema. Finalmente, en la tercera sección me detendré en la identificación de las causas que explican las condenas erróneas, intentando organizarlas en dos tipologías básicas.

\subsection{Información general de los casos.}

Un primer dato interesante para conocer los casos de revisión acogidos por la Corte Suprema se refiere al número y género de los condenados erróneamente que luego fueron exonerados. La tabla $\mathrm{n}^{\circ} 2$ presenta el resumen de esta materia.

\footnotetext{
${ }^{23}$ Para facilitar la lectura del texto principal no hago referencia en este momento a los casos sino que incluyo al final de este trabajo un anexo (anexo A) con un listado que identifica sus roles por año.

${ }^{24}$ Debe recordarse como señalé en la sección anterior que la gran mayoría de los recursos son desechados de plano por la Corte o resueltos por causas sin pronunciamiento de fondo.

${ }^{25} \mathrm{La}$ información disponible previa indicaba que para un período de alrededor de seis años entre 2007 y 2012 se habían identificado sólo 25 recursos de revisión acogidos. Véase DUCE, “¿Debiéramos”, cit. nota n 3, pp. 85-87.
} 
DUCE, Mauricio. "La condena de inocentes en Chile: una aproximación empírica a partir de los resultados de los recursos de revisión acogidos por la Corte Suprema en el período 2007-2013".

Tabla $\mathrm{n}^{\circ} 2$

$\mathrm{N}^{\mathrm{o}}$ hombres y mujeres por año en recursos de revisión acogidos años 2007-2013

Fuente: Elaboración propia a partir de datos del Poder Judicial

\begin{tabular}{|l|c|c|c|}
\hline Año & $\begin{array}{l}\mathbf{N}^{\mathbf{o}} \\
\text { hombres }\end{array}$ & $\begin{array}{l}\mathbf{N}^{\mathbf{o}} \\
\text { mujeres }\end{array}$ & $\mathbf{N}^{\mathbf{o}}$ total \\
\hline 2007 & 2 & 1 & 3 \\
\hline 2008 & 4 & 2 & 6 \\
\hline 2009 & 2 & 3 & 5 \\
\hline 2010 & 11 & 0 & 11 \\
\hline 2011 & 5 & 0 & 5 \\
\hline 2012 & 11 & 0 & 11 \\
\hline 2013 & 2 & 1 & 3 \\
\hline Total & $\begin{array}{c}\mathbf{3 7} \\
(\mathbf{8 4 , 1 \% )}\end{array}$ & $\begin{array}{c}\mathbf{7} \\
(\mathbf{1 5 , 9 \% )}\end{array}$ & $\begin{array}{c}\mathbf{4 4} \\
(\mathbf{1 0 0 \%})\end{array}$ \\
\hline
\end{tabular}

Dos hallazgos de interés de mencionar. En primer lugar, el número de condenados erróneamente coincide con el número total de casos acogidos por la Corte Suprema. En consecuencia, ninguno de estos casos cuenta con más de un condenado erróneo. El segundo hallazgo dice relación con la distribución de género, la que muestra una proporción bastante similar al porcentaje de hombres y mujeres que son objeto de persecución penal en el país. En efecto, según los datos que proporciona la Defensoría Penal Pública, el año 2013 habrían atendido a un $82,9 \%$ de hombres y a un $17,1 \%$ de mujeres ${ }^{26}$.

Un segundo dato relevante para conocer los casos de revisión acogidos por la Corte Suprema tiene que ver con identificar el tipo de delitos a los que los condenados erróneos fueron originalmente sancionados. La primera cuestión a constatar es que en 43 de los 44 casos la condena recayó en un sólo tipo de delito imputado, aún cuando en algunos casos se trató de un delito reiterado. Sólo en un caso (causa rol n 9562-2009) se condenó por dos delitos diversos (hurto y receptación), aún cuando recaen sobre un mismo bien jurídico.

Considerando los casos de reiteración como un sólo delito, el universo total de delitos condenados sería de 45. En este universo, la gran mayoría de las condenas recaen en delitos contra la propiedad de distinto tipo. Así, en 19 casos (42,2\% del total) se trató de condenas por diversos tipos de robos, incluyendo robos con violencia o intimidación (3), robos por sorpresa (2), robos en lugares habitados o destinados a la habitación (3), robos en lugares no destinados a la habitación (5) y robos en bienes nacionales de uso público (6). A ello se debe sumar 16 casos $(35,6 \%$ del total) en donde las condenas fueron por delitos de hurto por diversos montos. Finalmente, dos casos $(4,4 \%$ del total) se refirieron a delitos de receptación. En su conjunto, un poco más de un $83 \%$ se refiere a delitos contra la

26 DEFENSORÍA PENAL PÚBLICA, Memoria Anual 2013, p. 33, disponible en http://www.dpp.cl/resources/upload/files/documento/bd1eefb5a04f47e285d12fb10aa387c6.pdf (última visita el 23 de marzo de 2015). La misma fuente indica que desde el año 2008 en adelante la cifra ha tenido variaciones menores. 
Polít. crim. Vol. 10, № 19 (Julio 2015), Art. 6, pp. 159-191.

[http://www.politicacriminal.cl/Vol_10/n_19/Vol10N19A6.pdf]

propiedad. Si bien los delitos contra la propiedad representan los mayores flujos de ingreso del sistema, estos datos dan cuenta de una sobre representación de los mismos. Así, en el año 2013, los delitos contra la propiedad constituyeron sólo un 40,91\% del total de ingresos del Ministerio Público ${ }^{27}$. Si se consideran sólo los casos ingresados con imputado conocido, es decir los que tienen mayores posibilidades de llegar a una condena, los delitos contra la propiedad representaron un $18 \%$ del total de ingresos del Ministerio Público ese año ${ }^{28}$. Es probable que el mayo número de condenas erróneas en este tipo de delito obedezcan al tipo de procedimientos y causas de error que examinaré en secciones siguientes.

Otras categorías de delitos se distribuyen con cierta marginalidad. La tenencia o porte ilegal de armas es la más importante de ellas y cuenta con tres condenas erróneas $(6,7 \%$ del total), el giro doloso de cheques está presente en dos casos $(4,4 \%$ del total) y el delito de desacato previsto en el artículo 240 del Código de Procedimiento Civil, el de conducción en estado de ebriedad (art. 115 Ley $^{\circ}$ 18.290) y el delito uso de licencia de conducir falsa (artículo 192 letra b) de la Ley $\left.n^{\circ} 18.290\right)$ con uno cada uno (2,2\% del total cada uno).

Una tercera cuestión a indagar fue la identificación de las sanciones impuestas originalmente en las condenas. Las sanciones impuestas, junto con el tipo de delito imputado, pueden permitir evaluar la gravedad de los casos en donde se ha condenado a inocentes en nuestro país. La principal distinción en este tópico fue la de identificar si la pena principal era o no privativa de libertad y luego si, siendo privativa de libertad, ésta había sido de cumplimiento efectivo u objeto de una pena alternativa o sustitutiva. La tabla $\mathrm{n}^{\mathrm{o}} 3$ da cuenta del tipo de pena impuesta.

Tabla $\mathrm{n}^{\circ} 3$

Tipos penas impuestas en sentencias con recurso de revisión acogidos años 2007-2013 Fuente: Elaboración propia sobre la base de sentencias revisión acogidas 2007-2013

\begin{tabular}{|c|c|}
\hline $\begin{array}{c}\text { Pena privativa de } \\
\text { libertad } \\
\mathbf{N}^{\mathbf{0}} \mathbf{y}(\boldsymbol{\%})\end{array}$ & $\begin{array}{c}\text { Otro tipo de penas } \\
\mathbf{n}^{\mathbf{0}} \mathbf{y}(\boldsymbol{\%})\end{array}$ \\
\hline $37 \operatorname{casos}(84,1 \%)$ & 7 casos $(15,9 \%)$ \\
\hline
\end{tabular}

Como se puede apreciar, en la gran mayoría de los casos la pena principal fue privativa de libertad. Así, esto ocurrió en 37 de los 44 casos, es decir, en un 84,1\% del total. Cuando se analiza en detalle la pena concreta impuesta se puede apreciar bastante diversidad. La más grave impuesta corresponde a la de 10 años y un día de presidio mayor en su grado medio (causa rol $\mathrm{n}^{\circ}$ 12018-2011), en tanto que la más leve es de 21 días de prisión, la que se repite en cuatro casos (roles ${ }^{\circ}$ 8046-2010, 8807-2010, 8975-2010 y 2143-2012).

\footnotetext{
${ }^{27}$ MINISTERIO PÚBLICO, Boletín Estadístico Anual 2013, pp. 5 y 6 (tablas 3.1 y 3.2), disponible en http://www.fiscaliadechile.cl/Fiscalia/estadisticas/index.do (última visita el 23 de marzo de 2015).

${ }^{28}$ MINISTERIO PÚBLICO, "Boletín”, cit. nota n 27, p. 5 (tabla 3.1).
} 
DUCE, Mauricio. "La condena de inocentes en Chile: una aproximación empírica a partir de los resultados de los recursos de revisión acogidos por la Corte Suprema en el período 2007-2013".

Por otra parte, la tabla muestra como los casos en que se condenó a una pena diferente a la privación de libertad como pena principal fueron minoritarios: 7 de 44 (un 15,9\%). El análisis detallado de las mismas da cuenta que casi la totalidad corresponde a penas de multa (6 casos) y sólo una a una pena distinta que fue la de 40 horas de trabajo al servicio de la comunidad (causa rol n ${ }^{\circ}$ 5610-2010).

Si se considera como un universo total las penas privativas de libertad, se puede establecer que la distribución de éstas entre las que fueron de cumplimiento efectivo y las que fueron objeto de una pena alternativa (Ley $\mathrm{n}^{\circ} 18.216$ en su versión original previa a la modificación de la Ley $n^{\circ} 20.603$ que fue la vigente al momento de la gran mayoría de los casos) presenta una leve preferencia por las segundas. La tabla $\mathrm{n}^{\circ} 3$.A resume estos datos incluyendo el tipo de pena alternativa que se decretó en cada caso.

Tabla $n^{\circ}$ 3.A

Distribución penas privativas de libertad

Fuente: Elaboración propia sobre la base de sentencias revisión acogidas 2007-2013

\begin{tabular}{|c|c|c|}
\hline $\begin{array}{c}\text { Categoría de } \\
\text { pena privativa }\end{array}$ & $\mathbf{n}^{\circ} \mathbf{y} \%$ \\
\hline $\begin{array}{c}\text { Cumplimiento } \\
\text { efectivo }\end{array}$ & 15 \\
\hline $\begin{array}{c}\text { Pena alternativa } \\
\text { (Ley n }{ }^{\circ} \text { 18.216) }\end{array}$ & & $(40,5 \%)$ \\
\hline & Remisión condicional & 22 \\
& Reclusión nocturna & 13 \\
& $(35,1 \%)$ \\
\hline & Libertad vigilada & 8 \\
$(21,6 \%)$ \\
\hline Total & & 1 \\
& & $\mathbf{3 7} \%)$ \\
\hline & & $(\mathbf{1 0 0 \%})$ \\
\hline
\end{tabular}

Los datos sobre las penas impuestas en los casos de condenas erróneas contrastan con las cifras del Ministerio Público del año 2013. Estas cifras dan cuenta que las penas privativas de libertad con cumplimiento efectivo representan un margen bastante menor del total de las condenas de dicho año. Así, en los casos de imputados condenados que fueron llevados a audiencia de control de la detención, en un $44,75 \%$ se aplicó una pena privativa de libertad; en un 18,87\% adicional una pena privativa sustituida por alguna de las medidas de la Ley $\mathrm{n}^{\circ} 18.216$ y en un $36,38 \%$ se aplicó una multa ${ }^{29}$. Si se consideran en cambio los imputados condenados sin audiencia de control de la detención, los números indican que sólo un $18,17 \%$ fue condenado a pena privativa de libertad efectiva, un $11,19 \%$ a pena

${ }^{29}$ MINISTERIO PÚBLICO, “Boletín”, cit. nota no 27, p. 31 (tabla 6.10) 
Polít. crim. Vol. 10, № 19 (Julio 2015), Art. 6, pp. 159-191.

[http://www.politicacriminal.cl/Vol_10/n_19/Vol10N19A6.pdf]

privativa sustituida por alguna de las medidas de la Ley $\mathrm{n}^{\circ} 18.216$ y un $70,64 \%$ a una multa $^{30}$. Sumadas ambas categorías el total de penas privativas de libertad de cumplimiento efectivo llegó el año 2013 a un 33,3\% del total de condenas, las penas con medidas de la ley $\mathrm{n}^{\circ} 18.216$ representaron un $15,6 \%$ y las multas un $51,1 \%$. En consecuencia, estos datos parecen mostrar que en promedio los casos de revisión acogidos por la Corte Suprema serían en principio más graves que el promedio de condenas en el país considerando el año 2013 como base de comparación. Este hallazgo puede ser leído de diversas formas. Dentro de ellas me parece plausible afirmar la hipótesis que la acción o recurso de revisión tiende a ser utilizada como un mecanismo de control sólo en parte del universo total de las condenas, generalmente en casos en donde las consecuencias de las mismas son más graves. En casos menos graves en promedio los incentivos de los condenados y el funcionamiento del sistema parecieran no favorecer el uso de este mecanismo.

Una cuarta variable relevante para conocer el tipo de casos en que la Corte Suprema ha acogido una revisión en el período objeto de estudio, fue la de identificar el tipo de procedimientos en el cual se produjo la condena. Como es sabido, una de las características del nuevo sistema procesal penal es que este ofrece diversos caminos procesales por medio de los cuáles se puede llegar a una sentencia condenatoria. La tabla $\mathrm{n}^{\mathbf{0}} 4$ contiene un resumen de este tema distinguiendo en cuatro categorías de procedimientos.

Tabla $\mathrm{n}^{\circ} 4$

$\mathrm{N}^{\mathrm{o}}$ de recursos de revisión

acogidos por tipo de procedimientos años 2007-2013

Fuente: Elaboración propia sobre la base de sentencias revisión acogidas 2007-2013

\begin{tabular}{|c|c|c|c|c|c|}
\hline Año & Ordinario & Simplificado & Abreviado & Otros $^{31}$ & Total \\
\hline 2007 & 1 & 0 & 1 & 1 & 3 \\
\hline 2008 & 0 & 4 & 1 & 1 & 6 \\
\hline 2009 & 1 & 3 & 1 & 0 & 5 \\
\hline 2010 & 0 & 11 & 0 & 0 & 11 \\
\hline 2011 & 2 & 2 & 1 & 0 & 5 \\
\hline 2012 & 1 & 10 & 0 & 0 & 11 \\
\hline 2013 & 2 & 0 & 1 & 0 & 3 \\
\hline Total & $\mathbf{7}$ & $\mathbf{3 0}$ & $\mathbf{5}$ & $\mathbf{2}$ & $\mathbf{4 4}$ \\
& $(\mathbf{1 5 , 9 \% )}$ & $(\mathbf{6 8 , 2 \%})$ & $(\mathbf{1 1 , 4 \% )}$ & $\mathbf{( 4 , 5 \% )}$ & $\mathbf{( 1 0 0 \% )}$ \\
\hline
\end{tabular}

Los datos permiten apreciar que el procedimiento que aporta por lejos más condenas de inocentes es el simplificado ${ }^{32}$. Esto no debiera sorprender debido a la relevancia que este

\footnotetext{
${ }^{30}$ MINISTERIO PÚBLICO, "Boletín", cit. nota no 27, p. 32 (tabla 6.11)

31 Se incluye un caso de condena en procedimiento monitorio (causa rol $\mathrm{n}^{\mathrm{o}}$ 5049-2008) y otra en procedimiento por delito de acción privada (causa rol $\mathrm{n}^{\circ}$ 5546-2007).

${ }^{32}$ El procedimiento simplificado es un procedimiento especial contemplado en el CPP que resulta obligatorio para el caso de simples delitos en los que el Ministerio Público requiriere la aplicación de una pena que no exceda el presido o reclusión menor en su grado mínimo (540 días de privación de libertad). Se trata de un procedimiento que es resuelto por el juez de garantía y que representa una clara simplificación respecto al
} 
DUCE, Mauricio. "La condena de inocentes en Chile: una aproximación empírica a partir de los resultados de los recursos de revisión acogidos por la Corte Suprema en el período 2007-2013".

procedimiento ha ido adquiriendo en la práctica del sistema. En efecto, la información estadística disponible indica que el procedimiento simplificado se ha transformado con el tiempo en una de las principales fuentes de sentencias condenatorias en nuestro país. Así, de acuerdo a las estadísticas del Ministerio Público, del total de 230.640 sentencias condenatorias dictadas el año 2013, sólo 7.397 (un 3,2\% del total) fueron consecuencia de la realización de un juicio oral ordinario y el resto $(96,8 \%)$ son producto de la realización de procedimientos abreviados, simplificados y monitorios ${ }^{33}$. Según las cifras de la Defensoría Penal Pública del año 2012, el 38,6\% de los términos fue en sentencias en procedimiento simplificado, el $4,8 \%$ de abreviado, el $2,9 \%$ en monitorios y el $2,8 \%$ de juicios orales ${ }^{34}$. La mayor presencia porcentual de casos de juicio oral ordinario y abreviado en el universo de casos en análisis por sobre los procedimientos monitorios daría cuenta nuevamente que los casos de recursos de revisión acogidos tienden a darse en situaciones cuya gravedad es en promedio superior a los casos en que el sistema logra una condena. Esto reforzaría la hipótesis que he planteado previamente sobre la posibilidad que en delitos con penas más bajas exista una menor utilización de un mecanismo de este tipo y, por lo mismo, una posibilidad de una cifra negra más alta de condenas erróneas.

Finalmente, una última variable utilizada para la caracterización de los casos ha sido la de identificar su procedencia regional de los mismos. De esta forma, se pretende determinar si las condenas erróneas surgen como consecuencia de una realidad regional específica o representan un problema más extendido a nivel nacional. La tabla $\mathrm{n}^{\circ} 5$ resume los resultados obtenidos en esta materia.

Tabla $\mathrm{n}^{\mathrm{o}} 5$

Procedencia regional de recursos de revisión acogidos años 2007-2013

Fuente: Elaboración propia sobre la base de sentencias revisión acogidas 2007-2013

\begin{tabular}{|l|c|c|}
\hline \multicolumn{1}{|c|}{ Región } & $\mathbf{N}^{\circ}$ casos & $\begin{array}{c}\text { \% del } \\
\text { total }\end{array}$ \\
\hline RM & 26 & $59,1 \%$ \\
\hline VIII & 4 & $9,1 \%$ \\
\hline IX & 4 & $9,1 \%$ \\
\hline
\end{tabular}

procedimiento ordinario. Una explicación detallada de este procedimiento puede verse en DURAN, Rafael, Procedimiento simplificado y monitorio en el procedimiento penal chileno, Santiago: Librotecnia, 2009.

${ }^{33}$ MINISTERIO PÚBLICO, "Boletín", cit. nota no 27, pp. 13 y 34. Lamentablemente las cifras del Ministerio Público no se presentan en la actualidad de manera desagregada por tipo de procedimiento por lo que no es posible determinar cuántas de estas condenas provienen de cada uno de estos procedimientos. Cifras del año 2008 indican que las sentencias de procedimiento abreviado representaron el 16,6\% del total, las de simplificado el $38,5 \%$, las de procedimiento monitorio el $41,4 \%$ y las de juicio oral en procedimiento ordinario un 3,4\%. Estos datos pueden verse en DUCE, Mauricio, "Diez años de desarrollo de la reforma procesal penal en Chile: apuntes sobre su desarrollo, logros y objetivos", en: FUENTES, Claudio (Coord.), Diez años de reforma procesal penal en Chile. Santiago: Ediciones Universidad Diego Portales, 2011, pp. 2375 , p. 57.

${ }^{34}$ DEFENSORÍA PENAL PÚBLICA, "Informe", cit. nota no 15, p. 17. A ello hay que agregar que 50,5\% de los términos corresponde a formas anteriores al juicio oral en procedimiento ordinario. 
Polít. crim. Vol. 10, № 19 (Julio 2015), Art. 6, pp. 159-191.

[http://www.politicacriminal.cl/Vol_10/n_19/Vol10N19A6.pdf]

\begin{tabular}{|l|c|c|}
\hline V & 3 & $6,8 \%$ \\
\hline VII & 2 & $4,5 \%$ \\
\hline I & 2 & $4,5 \%$ \\
\hline II & 1 & $2,2 \%$ \\
\hline III & 1 & $2,2 \%$ \\
\hline IV & 1 & $2,2 \%$ \\
\hline $\begin{array}{l}\text { VI, X, XI, XII, } \\
\text { XIII y XIV }\end{array}$ & 0 & $0 \%$ \\
\hline Total & $\mathbf{4 4}$ & $\mathbf{1 0 0 \%}$ \\
\hline
\end{tabular}

Las cifras tienden a mostrar una fuerte concentración de los casos en las regiones con mayor población, como lo son la Región Metropolitana, la V y la VIII región. Entre las tres se explican el $76 \%$ de las condenas erróneas. Esto es más o menos obvio ya que se trata de las regiones que mayor flujo de casos manejan. Con todo, su contribución a las sentencias erróneas pareciera superar con creces la proporción de casos que ellas manejan de acuerdo a los ingresos del Ministerio Público. Así, en el año 2013 estas tres regiones representaron sólo el $62,2 \%$ del total de ingresos a nivel nacional ${ }^{35}$. En el otro extremo, es llamativo que seis regiones no contribuyan a la condena de inocentes (VI, X, XI, XII, XIII y XIV regiones).

Cuando se hace un análisis desagregado por región, la Región Metropolitana aparece por lejos como la más problemática en materia de producción de condenas erróneas, incluso superando muy significativamente el nivel de ingresos de esta misma. Así, los datos del Ministerio Público en el año 2013 dan cuenta que la Región Metropolitana representó el $40,6 \%$ de los ingresos, es decir, se presenta una diferencia de casi $20 \%$. Algo similar ocurre con la IX región que representa sólo un 5,0\% de los ingresos del Ministerio Público y la I región que tiene un 2,9\%. La VIII región presenta una tasa bastante similar ya que sus ingresos del 2013 representaron el 10,8\% del sistema. La V región, en cambio, tiene un porcentaje de ingresos mayor al que tiene su participación en las condenas erróneas $(10,8 \%$ vs. $6,8 \%)^{36}$. Es difícil obtener conclusiones muy definitivas y profundas a partir de estos datos. No obstante esto, me parece que sí es posible afirmar que, a pesar de las diferencias entre porcentajes de condenas e ingresos, los casos de recursos de revisión acogidos dan cuenta de problemas de funcionamiento del sistema de relativa extensión nacional, aún cuando con un aporte muy significativo de la Región Metropolitana.

\subsection{Información sobre los recursos de revisión.}

En esta segunda sección entrego alguna información sobre los recursos de revisión acogidos por la Corte Suprema en el período en estudio. Debo recordar que el propósito de esta investigación no es conocer la dinámica de funcionamiento de esta acción, sino más bien obtener datos empíricos que permiten dimensionar y conocer el problema de las condenas erróneas en nuestro país. Es por eso que en este tema sólo he indagado respecto a

\footnotetext{
${ }^{35}$ Los datos sobre los ingresos del año 2013 han sido calculados sobre la base de las estadísticas oficiales del Ministerio Público del año 2013. MINISTERIO PÚBLICO, "Boletín”, cit. nota no 27, p. 2.

${ }^{36}$ MINISTERIO PÚBLICO, “Boletín”, cit. nota n 27, p. 2.
} 
DUCE, Mauricio. "La condena de inocentes en Chile: una aproximación empírica a partir de los resultados de los recursos de revisión acogidos por la Corte Suprema en el período 2007-2013".

dos cuestiones que me parecen las más relevantes: quienes interpusieron el recurso de revisión y la causal por la cual éste fue acogido. Hay un conjunto de otros temas que podrían ser de interés examinar pero que me alejarían del propósito básico de este trabajo.

Una de las particularidades que presenta el recurso de revisión en relación a vías de impugnación "normales" de una sentencia definitiva es que puede ser interpuesto por diversos actores en favor del imputado. En efecto, el artículo 474 del CPP permite que la revisión pueda ser solicitada por el Ministerio Público, el condenado o por el cónyuge, ascendientes, descendientes o hermanos de éste. Para facilitar el análisis, durante la investigación distinguí dos categorías: casos en que el recurso fue solicitado por el Ministerio Público y casos en que fue requerido por la "defensa". Esta última categoría inclúi los casos en que el recurso fue presentado por propio condenado, su defensor o familiares. La tabla $\mathrm{n}^{\circ} 6$ contiene el resumen de los resultados obtenidos.

Tabla $n^{\circ} 6$

$\mathrm{N}^{\circ}$ de recursos de revisión por tipo de parte que los presentó de los recursos acogidos años 2007-2013

Fuente: Elaboración propia sobre la base de sentencias revisión acogidas 2007-2013

\begin{tabular}{|c|c|c|c|}
\hline Año & MP & Defensa & $\mathbf{N}^{\mathbf{0}}$ total \\
\hline 2007 & 2 & 1 & 3 \\
\hline 2008 & 4 & 2 & 6 \\
\hline 2009 & 2 & 3 & 5 \\
\hline 2010 & 10 & 1 & 11 \\
\hline 2011 & 2 & 3 & 5 \\
\hline 2012 & 9 & 2 & 11 \\
\hline 2013 & 1 & 2 & 3 \\
\hline Total & $\mathbf{3 0}$ & $\mathbf{1 4}$ & $\mathbf{4 4}$ \\
& $(\mathbf{6 8 , 1 \% )}$ & $\mathbf{( 3 1 , 8 \% )}$ & $(\mathbf{1 0 0 \% )}$ \\
\hline
\end{tabular}

La cuestión más llamativa de estos datos es que en un porcentaje muy mayoritario de los casos son los propios fiscales del Ministerio Público (normalmente el fiscal regional de la región respectiva) quienes interponen el recurso al momento de haber constatado que se ha cometido un error. En un sistema como el nuestro que ha ido adquiriendo fuertes tintes adversariales, podría esperarse que no sean los fiscales quienes tengan un liderazgo en la materia. Dos consideraciones sobre esto. En primer término, esta situación podría explicarse en una buena medida respecto al tipo de errores o las causas que han generado las revisiones, lo que se podrá apreciar de mi análisis en la próxima sección del trabajo ${ }^{37}$. No obstante esto, debo igualmente destacar que se trata de una tendencia muy positiva en la medida que da cuenta disposición de los fiscales de corregir errores que puedan haber

\footnotetext{
${ }^{37}$ En 29 de los 30 casos se trató de recursos interpuestos en situaciones de suplantación de identidad. Sólo en uno de ellos el recurso impugnó una condena basada en una causa diferente (rol n 6720-2012). La diferencia entre estos casos se explicará en detalle en la próxima sección.
} 
Polít. crim. Vol. 10, № 19 (Julio 2015), Art. 6, pp. 159-191.

[http://www.politicacriminal.cl/Vol_10/n_19/Vol10N19A6.pdf]

cometido, no importando su naturaleza, y que constituye un activo institucional pensando a futuro en la necesidad de avanzar en una agenda de cambios mas ambiciosa en la materia.

Un segundo tema que fue objeto de análisis respecto a los recursos de revisión fue el de identificar la causal que en definitiva fue acogida por la Corte Suprema. El artículo 473 del CPP establece cinco hipótesis posibles ${ }^{38}$. No obstante ello, el $100 \%$ de los recursos fue acogido por la causal de la letra d) que establece que procede la revisión cuando "....con posterioridad a la sentencia condenatoria, ocurriere o se descubriere algún hecho o apareciere algún documento desconocido durante el proceso, que fuere de tal naturaleza que bastare para establecer la inocencia del condenado". En dos de esos casos, que se trataron de recursos interpuestos por defensores, además se invocó la causal de la letra a) del artículo 478 del CPP pero la Corte Suprema estimó no se configuraba (causas rol nº 6368-2008 y 5740-2010).

La causal acogida permite comprender varias cuestiones mencionadas previamente. La primera es que explica el porqué en todos los casos la Corte -al acoger el recurso- haya dictado también sentencia de reemplazo. Esta causal procede en la medida en que el nuevo hecho o antecedente que se invoca sea de tal magnitud que por sí solo establezca la inocencia del condenado, por lo mismo si ella es demostrada lo que la Corte debe hacer es dictar sentencia de reemplazo según menciona el artículo 478 del CPP. En segundo lugar, se muestra que más allá de una amplitud aparente del recurso por la existencia de cinco causales que lo hacen procedente, en la práctica la única causal que ofrece posibilidades reales de obtener exoneración es la letra d), lo que tiende a ratificar lo estricto y difícil que es obtener por esta vía una exoneración en nuestro país.

\subsection{Causas que explican las condenas erróneas.}

Uno de los temas que ha generado mayor cantidad de investigación en el ámbito comparado ha sido la de identificar las causas que producen la condena de inocentes ${ }^{39}$. En general,

${ }^{38}$ El artículo establece lo siguiente: Artículo 473.- Procedencia de la revisión. La Corte Suprema podrá rever extraordinariamente las sentencias firmes en que se hubiere condenado a alguien por un crimen o simple delito, para anularlas, en los siguientes casos:

a) Cuando, en virtud de sentencias contradictorias, estuvieren sufriendo condena dos o más personas por un mismo delito que no hubiere podido ser cometido más que por una sola;

b) Cuando alguno estuviere sufriendo condena como autor, cómplice o encubridor del homicidio de una persona cuya existencia se comprobare después de la condena;

c) Cuando alguno estuviere sufriendo condena en virtud de sentencia fundada en un documento o en el testimonio de una o más personas, siempre que dicho documento o dicho testimonio hubiere sido declarado falso por sentencia firme en causa criminal;

d) Cuando, con posterioridad a la sentencia condenatoria, ocurriere o se descubriere algún hecho o apareciere algún documento desconocido durante el proceso, que fuere de tal naturaleza que bastare para establecer la inocencia del condenado, $y$

e) Cuando la sentencia condenatoria hubiere sido pronunciada a consecuencia de prevaricación o cohecho del juez que la dictó o de uno o más de los jueces que concurrieron a su dictación, cuya existencia hubiere sido declarada por sentencia judicial firme.

${ }^{39}$ La literatura con investigación empírica en la materia es muy extensa. Uno de los textos más recientes realiza un estudio detallado de casos, incluyendo el estudio de los antecedentes y transcripciones de los primeros 250 casos exonerados por el Innocence Project, puede verse en GARRET, Brandon, Convicting the Innocent, Cambridge: Harvard University Press, 2011, 367 pp. Otro estudio empírico relevante, realizado sobre una base de datos más amplia de casos puede verse en GROSS, Samuel; SCHAFFER, Michael, 
DUCE, Mauricio. "La condena de inocentes en Chile: una aproximación empírica a partir de los resultados de los recursos de revisión acogidos por la Corte Suprema en el período 2007-2013".

parece haber un acuerdo importante en que los principales factores que incidirían en la producción de condenas erróneas serían seis. Estos incluirían: (1) problemas con la identificación ocular de imputados por parte de víctimas y testigos; (2) uso de prueba pericial de baja calidad o confiabilidad; (3) uso de confesiones falsas; (4) uso de testigos mentirosos o poco confiables; (5) mal trabajo de las agencias de persecución penal; e, (6) inadecuada representación legal de los condenados. La doctrina nacional que se ha preocupado del tema también concuerda con la relevancia de estos factores o causas para el caso nacional ${ }^{40}$. En la misma dirección, el Proyecto Inocentes de la Defensoría Penal Pública ha ocupado estas mismas categorías para identificar la causa principal del error en los casos que ha registrado en su página $w_{e} b^{41}$.

El análisis de los 44 casos de revisión acogidos por la Corte Suprema permite observar que las causas que explican las condenas erróneas presentan algunas diferencias con la información disponible en el ámbito comparado que mencioné en los párrafos previos. Para efectos de presentar de manera más ordenada la información obtenida, organizaré la presentación de los casos en dos grupos o tipologías ${ }^{42}$.

2.3.1. Casos de condenas erróneas basadas en la suplantación de identidad.

Una porción mayoritaria de los casos, 36 de 44, que corresponden al 81,8\% del total, se refieren a situaciones en que la Corte Suprema revocó condenas erróneas respecto de

Exonerations in the United States 1989-2012, 2012, 108 pp. Disponible en http://www.law.umich.edu/special/exoneration/Documents/exonerations us 19892012 full report.pdf

(última visita 23 de marzo de 2015). En este trabajo se hace un análisis sistemático de los primeros 873 casos registrados en el "National Registry of Exonerations" (Registro Nacional de Exoneraciones) de los Estados Unidos, que corresponde a un proyecto conjunto llevado adelante por las facultades de derecho de las universidades de Michigan y Northwestern destinado a identificar y registrar casos de personas inocentes condenadas y luego exoneradas en dicho país a partir del año 1989. Al 23 de marzo de 2015 se había $\begin{array}{lllll}\text { registrado } & 1.569 & \text { casos } & \text { de } & \text { exoneraciones. }\end{array}$ http://www.law.umich.edu/special/exoneration/Pages/about.aspx (última visita 23 de marzo de 2015). Un análisis de la literatura disponible en la materia en donde se concluye el acuerdo el punto puede verse en ACKER, James et. al, "Stepping Back - Moving beyond immediate causes: criminal justice and wrongful convictions in social context", en: REDLICH, Allison et. al, Examining Wrongful Convictions, Durham: Carolina Academic Press, 2014, pp. 3-15, pp. 6-7.

${ }^{40}$ DUCE, “¿Debiéramos”, cit. nota no 3 y CASTILLO, "Enjuiciando”, cit. nota n 3.

${ }^{41}$ En orden de importancia estadística, los casos del Proyecto Inocentes dan cuenta de las siguientes causas: los problemas de identificación errónea representan el 35\% de los casos (14); la declaración falsa de víctimas o testigos el 27,5\% de los casos (11); la mala conducta de los agentes del Estado representa un 22,5\% de los casos (9); los errores periciales un 10\% (4) y las confesiones falsas y mal comportamiento del defensor un $2,5 \%$ cada uno (1). Estos datos se obtienen del análisis de la información disponible en http://www.proyectoinocentes.cl/casos/listado/page/1 (última visita el 23 de marzo de 2015). Cabe tener presente que este proyecto sólo consigna lo que se denomina como "causa principal" del error. Esto limita la identificación de las potenciales causas ya que los estudios comparados sobre la materia indican que es bastante común en los casos de condenas erróneas acreditados que concurran varias causas al mismo tiempo y no sólo una. Véase SIMON, Dan, In Doubt: The Psychology of the Criminal Justice Process, Cambridge: Harvard University Press, 2012, 367 pp., p. 7.

${ }_{42}$ Al finalizar el trabajo se incluirá un anexo específico (anexo b) con la identificación de los casos agrupándolos de acuerdo al criterio que he planteado en estas páginas. 
Polít. crim. Vol. 10, № 19 (Julio 2015), Art. 6, pp. 159-191.

[http://www.politicacriminal.cl/Vol_10/n_19/Vol10N19A6.pdf]

personas que habían suplantado la identidad de otras sin que el sistema pudiera percatarse de aquello.

La causa del error en estos casos supone un escenario bastante particular que describo a continuación. Se trata de situaciones en que personas que son atrapadas por el sistema (típicamente en flagrancia), dan un nombre que han tomado de otra persona que no ha participado en el delito y el sistema no es capaz de darse cuenta de esto. Ello se logra normalmente falsificando o dando uso incorrecto del número de carné de identidad del inocente suplantado. Esto lleva a que formalmente sea condenada la persona que fue atrapada por el sistema, pero oficialmente es la persona cuya identidad ha sido suplantada por el verdadero autor. De esta forma, lo que suele ocurrir es que las personas inocentes cuya identidad fue suplantada se dan cuenta con posterioridad que existe una condena en su contra a través de distintas vías. Por ejemplo, muchas de ellas fueron detenidas en diversas circunstancias y luego encarceladas por períodos variables de tiempo hasta que pudieron demostrar al tribunal que la persona condenada originalmente había sido alguien que la había suplantado. A partir del conocimiento de la condena en su contra se presentan luego los recursos de revisión destinados a revertir las respectivas sentencias condenatorias.

Por lo general, se trata de casos en delitos contra la propiedad, con penas privativas de libertad bajas y que fueron llevadas adelante en procedimientos simplificados en el que el suplantador reconoció responsabilidad de acuerdo al artículo 395 del CPP, lo que permitió se dictara sentencia sin necesidad de realizar una audiencia de juicio y en una etapa muy temprana del proceso con poco tiempo para haber verificado la identidad del supuesto autor $^{43}$. Es posible apreciar, además, que en varios de los casos los suplantadores de identidad tienen alguna relación con el suplantado (por ejemplo son familiares, dentro de los que se incluyen hermanas y hermanos).

Este escenario podría dar lugar a discursos de minimización de la gravedad del problema. En efecto, alguien podría sostener que es comprensible en alguna medida que en procedimientos tan acelerados como los simplificados con reconocimientos de responsabilidad y por delitos que suponen penas bajas -como la multa o privativas de libertad de menor entidad-se puedan cometer este tipo de errores. De hecho, situaciones de esta naturaleza no son del todo desconocidas en la experiencia comparada. Así, por ejemplo, un estudio de condenas erróneas en casos de menor gravedad llevados adelante mediante procedimientos simplificados en Suiza del año 2007 dio cuenta que una de las causales principales de error fue la identificación incorrecta de los imputados debido a confusiones de nombre ${ }^{44}$.

\footnotetext{
${ }^{43}$ Dentro de las reglas del procedimiento simplificado, el artículo 395 del CPP permite que en la primera audiencia, luego de formulado el requerimiento de parte del fiscal, el imputado pueda aceptar responsabilidad en los hechos contenidos en el requerimiento, lo cual habilita al tribunal a dictar sentencia inmediata en la que no se puede imponer una pena superior a la solicitada por el fiscal. El artículo 393 bis permite, en los casos de flagrancia, que el requerimiento pueda ser presentado verbalmente por el fiscal en la misma audiencia de control de la detención. En consecuencia, en esas hipótesis si es que el imputado acepta responsabilidad el caso podría estar concluido con sentencia en menos de 24 horas desde la comisión del delito. Una explicación detallada de este procedimiento puede verse en DURAN, Procedimiento simplificado, cit. nota $\mathrm{n}^{\mathbf{o}} 32$.

${ }^{44}$ Estudio citado por GILLIÉRON, Gladys, "The risk of summary proceedings, plea bargaining and penal orders in producing wrongful convictions in U.S and Europe”, en: HUFF, Ronald y KILLIAS, Martin (Eds.),
} 
DUCE, Mauricio. "La condena de inocentes en Chile: una aproximación empírica a partir de los resultados de los recursos de revisión acogidos por la Corte Suprema en el período 2007-2013".

No obstante lo anterior, cuando se revisa el detalle de cada caso es posible apreciar como muchos de ellos salen de estos patrones, mostrando situaciones bastante más graves. Así, en varios casos las condenas fueron a penas privativas de libertad de extensión significativa. Por ejemplo, en dos casos el suplantado fue condenado a tres años y un día de presidio menor en su grado máximo por sendos delitos de robo en lugar habitado (causas rol $\mathrm{n}^{\circ}$ 3788-2007 y rol no 2030-2012). En otros dos casos, el suplantado fue condenado a tres años de presidio menor en su grado medio, uno por el mismo delito anterior (causa rol $\mathrm{n}^{\circ} 9502$ 2011) y otro por robo con intimidación (causa rol n ${ }^{\circ}$ 9022-2013). Además, hay otro caso en que la condena impone 541 días de presidio menor en su grado medio por el delito robo por sorpresa (causa rol $n^{\circ}$ 7627-2009). Se puede apreciar se trata de una cantidad relevante de casos en los que no se está en presencia de delitos menores para nuestra legislación ni de condenas insignificantes.

Junto con lo anterior, hay otros casos en donde la condena no se generó como consecuencia de un procedimiento simplificado con reconocimiento de responsabilidad. En varios casos ella es producto de un procedimiento abreviado (casos rol $\mathrm{n}^{\circ}$ 3788-2007; rol $\mathrm{n}^{\mathrm{o}}$ 1494-2008, rol $n^{\circ}$ 2740-2009; rol $n^{\circ}$ 9502-2011; y, rol no 9022-2013). Además, hay un caso donde incluso se condenó erróneamente como consecuencia de la realización de un juicio oral ordinario ante un Tribunal Oral en lo Penal (causa rol n 2030-2012).

Esta evidencia da cuenta que no estamos en presencia de un problema menor o comprensible por la poca relevancia de los casos o exclusivamente por la dinámica del procedimiento simplificado. Se trata de situaciones que parecen obedecer a problemas bastante gruesos de trabajo y coordinación entre las agencias del sistema que, por lo mismo, cuesta entender que se hayan mantenido en el tiempo. Por ejemplo, en el anexo B se puede apreciar que de las 11 revisiones acogidas el 2012, nueve se explican por esta causa. Es decir, a más de diez años de la puesta en marcha de nuestro CPP acusatorio, el sistema no ha tenido capacidad para resolver este tema tan grueso y básico de trabajo.

Afortunadamente, de acuerdo a la información que dispongo, las instituciones del sistema ya han comenzado a tomar cartas en el asunto para evitar que a futuro se sigan repitiendo problemas de este tipo y esto explicaría la disminución importante de casos de este tipo en el último tiempo, por ejemplo, que el año 2013 sólo se haya acogido sólo un caso en sede revisión de suplantación de identidad ${ }^{45}$.

Wrongful conviction and miscarriages of justice: causes and remedies in North American and European criminal justice systems. New York: Routledge, 2013, pp. 237-258, p. 243.

${ }^{45}$ En esta dirección, la Comisión Nacional Coordinadora del Sistema de Justicia Penal, en su sesión del 12 de mayo de 2014, acordó retomar un trabajo ya iniciado en materia de verificación de identidad de personas imputadas y condenadas para evitar los casos de suplantación de identidad. Véase MINISTERIO DE JUSTICIA, Ord. $\mathrm{n}^{\circ} 3824$ del Ministerio de Justicia de 3 de junio de 2014 en respuesta a Oficio ${ }^{\circ} 975$ de la Cámara de Diputados (documento en formato electrónico en poder del autor). En una exposición más reciente, realizada el 27 de agosto de 2014 en el contexto del Primer Encuentro de Cooperación Interinstitucional 2014 organizado por la Red Latinoamericana de Jueces (REDLAJ), el Fiscal Regional Andrés Montes - cabeza de la Fiscalía Regional Metropolitana Centro Norte- sostuvo que a partir del mes de septiembre se esperaba que Gendarmería de Chile tendría implementado un sistema denominado "CrossMatch" que permitiría resolver parte importante del problema de las suplantaciones de identidad. 
Polít. crim. Vol. 10, № 19 (Julio 2015), Art. 6, pp. 159-191.

[http://www.politicacriminal.cl/Vol_10/n_19/Vol10N19A6.pdf]

No obstante la gravedad de este tipo de condenas erróneas, ellas representan una situación muy especial como se ha podido apreciar, en la que se observa una lógica bastante distinta a los casos investigados como regla general en el ámbito comparado. En este contexto, avanzo ahora a la segunda tipología de casos.

\subsubsection{Casos de condenas erróneas basadas en otras causas.}

Un segundo grupo de casos corresponde a situaciones más similares a las descritas en la experiencia comparada aún cuando no en todos ellos como se verá. Se trata de un universo total de ocho condenas erróneas que representarían el 18,2\% del total de revisiones acogidas en el período 2007-2013. Es interesante constatar que de estos ocho casos, siete se han producido a partir del año 2011 lo que da cuenta que esta tipología ha surgido como un fenómeno más bien reciente en el funcionamiento del sistema. En esta dirección, de los tres casos acogidos por la Corte Suprema el año 2013, dos corresponden a este grupo de errores.

Antes de señalar algo sobre las causas que explican las condenas en estos casos, describo brevemente en un párrafo cada uno de ellos de manera que el lector tenga información de contexto general sobre los mismos. La presentación se hace en orden cronológico de acuerdo a la fecha en que el recurso de revisión fue acogido.

Caso Rafael Tapia (causa rol no 5546-2007): condenado el 27 de abril de 2007 por el Juzgado de Garantía de Linares en procedimiento simplificado a la pena de 541 días de presidio menor en su grado medio y accesorias como autor del delito de giro doloso de cheques, otorgándosele la reclusión nocturna. El recurso de revisión fue acogida por la Corte Suprema en forma unánime el 3 de abril de 2008, al acreditarse que el condenado había hecho pago íntegro de lo adeudado con anterioridad a que se encontrare ejecutoriada la sentencia condenatoria, por lo que el caso debió haberse sobreseído definitivamente.

Caso Claudio Jiménez (causa rol no 1558-2011): condenado el día 15 de noviembre de 2009 por el Tribunal Oral en lo Penal de Concepción en juicio oral ordinario como autor del delito de tenencia ilegal de arma de fuego previsto y sancionado en los artículos 5 y 9 de la Ley $\mathrm{n}^{\mathrm{o}} 17.798$ a la pena de 541 días de presidio menor en su grado medio y accesorias, pena privativa de libertad de cumplimiento efectivo. El recurso de revisión fue acogida por la Corte Suprema en forma unánime el 13 de abril de 2011, al acreditarse que el condenado tenía inscrita el arma a su nombre y contaba con autorización vigente para ser mantenida en su domicilio. El señor Jiménez había sido también condenado en el mismo juicio como autor del delito de tráfico de estupefacientes a la pena de 8 años de presidio mayor en su grado mínimo, decisión que no fue objeto de revisión.

Caso Diego Nieto (causa rol n ${ }^{\circ} 2227-2011$ ): condenado el día 5 de octubre del año 2010 por el Séptimo Juzgado de Garantía de Santiago en procedimiento simplificado a 60 días de prisión en su grado máximo y a una multa, pena remitida, como autor del delito de conducción en estado ebriedad previsto y sancionado en el artículo 115 a) de la Ley $n^{\circ}$ 18.290. El recurso de revisión fue acogida por la Corte Suprema en votación dividida de tres a dos el 24 de mayo de 2011, al acreditarse que el condenado había sido sobreseído definitivamente por el mismo tribunal como consecuencia del cumplimiento de una 
DUCE, Mauricio. "La condena de inocentes en Chile: una aproximación empírica a partir de los resultados de los recursos de revisión acogidos por la Corte Suprema en el período 2007-2013".

suspensión condicional del procedimiento decretada varios meses antes de realizar el procedimiento simplificado en su contra.

Caso Pedro Lobos (causa rol n ${ }^{\circ}$ 12018-2011): condenado el día 22 de febrero de 2008 por el $5^{\circ}$ Tribunal Oral en lo Penal de Santiago como autor de tres delitos de robo con intimidación a la pena de 10 años y un día de presidio mayor en su grado medio más la inhabilitación absoluta perpetua para cargos y oficios públicos y derechos políticos y la de inhabilitación absoluta para profesiones titulares durante el plazo de duración de la condena. El recurso de revisión fue acogido con unanimidad por la Corte Suprema el 22 de febrero de 2012, decisión que le permitió obtener su libertad, habiendo cumplido más de tres años de la condena impuesta. La Corte estableció la inocencia de Lobos considerando como un punto central la condena en un procedimiento paralelo de otra persona por delitos idénticos a los imputados a Lobos en fechas simultáneas, en el mismo lugar geográfico y en donde dicho condenado había confesado dichos delitos y, además, debido a que presentaba las mismas características físicas descritas por las presuntas víctimas de Lobos.

Caso Jorge Scalpello (causa rol no 8884-2012): condenado el día 18 de mayo de 2011 por el Octavo Juzgado de Garantía de Santiago como autor del delito reiterado de giro doloso de cheques a cumplir la sanción de 541 días de presidio menor en su grado medio y accesorias de suspensión de cargo u oficio público durante el tiempo de la condena. El recurso de revisión fue acogida por la Corte Suprema en forma unánime el 18 de febrero de 2013 al acreditarse que la gestión preparatoria de notificación del protesto de cheque había sido anulada por el Décimo Noveno Juzgado de Santiago con anterioridad a la condena pero que fue notificada al condenado con posterioridad a ella.

Caso Jorge Antio (causa rol no 6720-2013): condenado el día 27 de julio de 2012 por el Juzgado de Garantía de San Bernardo en procedimiento simplificado con reconocimiento de responsabilidad como autor del delito flagrante de desacato previsto en el artículo 240 del Código de Procedimiento Civil por el incumplimiento de la medida cautelar decretada en conformidad al artículo 10 de la Ley $n^{\circ} 20.066$ (Ley sobre Violencia intrafamiliar) a la pena de 61 días de presidio menor en su grado mínimo y la accesoria legal de suspensión de cargo u oficio público durante la condena, pena sustituida por la de reclusión parcial nocturna de la ley $\mathrm{n}^{\circ} 18.216$, consistiendo su encierro en la permanencia en su domicilio o residencia entre las 22:00 horas y 06:00 del día siguiente. El recurso de revisión fue acogido unánimemente por la Corte Suprema el día 23 de enero de 2013 al acreditarse que la medida cautelar no estaba vigente al momento de su supuesto incumplimiento. El señor Antio estuvo un día privado de libertad como consecuencia del caso.

Caso Víctor Moreno (causa rol no 4308-2013): condenado el día 22 de abril de 2013 por el Séptimo Juzgado de Garantía de Santiago en procedimiento simplificado con reconocimiento de responsabilidad como autor del delito uso de licencia de conducir falsa previsto en el artículo 192 letra b) de la ley 18.290 a la pena de 61 días de presidio menor en su grado mínimo, más accesorias legales, multa de un tercio de UTM e inhabilitación para obtener su licencia de conducir por el plazo de un año, pena de cumplimiento efectivo al no reunirse los requisitos para aplicar alguna medida alternativa prevista en la Ley $\mathrm{n}^{\circ}$ 
Polít. crim. Vol. 10, № 19 (Julio 2015), Art. 6, pp. 159-191.

[http://www.politicacriminal.cl/Vol_10/n_19/Vol10N19A6.pdf]

18.216. El recurso de revisión fue acogido unánimemente por la Corte Suprema el 22 de agosto de 2013 al establecerse que la licencia de conducir que portaba era auténtica. El señor Moreno estuvo un día privado de libertad como consecuencia del caso.

Caso Julio Robles (causa rol no 11.109-2013): condenado el día 12 de junio de 2012 por la segunda sala del Tribunal de Juicio Oral en lo Penal de Copiapó como autor del delito de robo por intimidación a la pena de cinco años y un día de presidio mayor en su grado mínimo, más las accesorias de inhabilitación absoluto perpetua para cargos y oficios públicos y derechos políticos y la de inhabilitación absoluta para profesiones titulares durante el período de duración de la condena. La Corte Suprema acogió un recurso de revisión en un voto de mayoría de cuatro a uno el día 14 de enero de 2014, decisión que le permitió obtener su libertad luego de haber pasado 459 días preso. La Corte estableció la inocencia de Robles considerando como un punto central la declaración de una de las víctimas que afirmó haberse equivocado en el procedimiento de reconocimiento seguido adelante en la investigación al haber observado al verdadero autor del delito en momentos que Robles ya estaba condenado y preso.

Según se puede apreciar luego de este breve recuento, se trata de casos bastante heterogéneos tanto en el tipo de procedimientos, delitos imputados y penas impuestas. De la lectura de las sentencias de revisión de los mismos, por otra parte, se pueden apreciar la concurrencia de varios de los factores identificados en el ámbito comparado como causa de errores, pero también algunos problemas cuya descripción no aparece en tal literatura. Dentro de los primeros hay cuatro de las seis causas surgen como potenciales explicaciones de los errores. A continuación me referiré brevemente a ellas considerando, como señalé en la introducción, que esta investigación no pretende realizar un estudio de casos sino avanzar en una caracterización preliminar de los mismos.

En primer lugar, los casos de Pedro Lobos y Julio Robles muestran la existencia de problemas en los procedimientos de reconocimiento llevados adelante en sede policial que pudieron traducirse en la condena equivocada de los mismos. Así, la Corte Suprema estimó que los procesos de reconocimiento fotográfico llevados adelante en el caso de Pedro Lobos no eran confiables y que era notorio el error en su evaluación por parte del tribunal oral $^{46}$. Incluso más, la Corte consideró se trataba de un procedimiento en donde hubo posiblemente inducción ${ }^{47}$. En el caso de Julio Robles, por su parte, la Corte Suprema consideró que se cumplió con el supuesto del artículo 473 letra d) del CPP por considerar que el error producido en el reconocimiento de una de las víctimas constituía un hecho nuevo desconocido al momento de dictarse la condena. La Corte señala que "Si tales antecedentes hubieran sido ponderados por el sentenciador de primer grado, no habría llegado a la sentencia condenatoria que legitimó en su momento la dictación de la sentencia cuya revisión se ha pedido, dictando por el contrario sentencia de absolución. ${ }^{48, "}$

Los casos de Jorge Antio y Víctor Moreno dan cuenta de un segundo problema, el de las confesiones falsas de los condenados, en este caso producidas en el formato de

\footnotetext{
${ }^{46}$ CORTE SUPREMA, sentencia de 22 de febrero de 2012, causa rol $\mathrm{n}^{\mathrm{o}}$ 12018-2011, considerando octavo.

${ }^{47}$ CORTE SUPREMA, sentencia de 22 de febrero de 2012, causa rol $n^{\circ} 12018-2011$, considerando quinto.

${ }^{48}$ CORTE SUPREMA, sentencia de 14 de enero de 2014, causa rol $n^{\circ} 11.109-2013$, considerando quinto.
} 
DUCE, Mauricio. "La condena de inocentes en Chile: una aproximación empírica a partir de los resultados de los recursos de revisión acogidos por la Corte Suprema en el período 2007-2013".

"reconocimientos de responsabilidad" en procedimientos simplificados de conformidad al artículo 395 del CPP. En efecto, en ambos casos nos encontramos con un reconocimiento de responsabilidad por delitos inexistentes. Víctor Moreno reconoce portar una licencia falsa que no lo era y Jorge Antio incumplir una medida cautelar no vigente. Esto genera dudas y cuestionamientos acerca del entorno en el que se producen estos reconocimientos de voluntad en procedimientos simplificados que hacen que personas estén dispuestas a reconocer delitos que no hay cometido. En ambos casos nos encontramos con personas que son detenidas el día anterior a la audiencia y que en esa calidad (privados de libertad) son conducidas a la misma. Se trata de audiencias que se llevan a efecto de manera bastante vertiginosa y breve, con poca información, en un lenguaje que hace que sólo los iniciados puedan entender con claridad qué es lo que pasa en el desarrollo de las mismas, en donde los imputados han tenido poco o nulo contacto previo con sus defensores y en las que se presentan requerimientos de parte del Ministerio Público con una solicitud de pena que representa una baja muy sustancial respecto a la potencial pena que en abstracto se podría exigir de acuerdo a los tipos penales imputados ${ }^{49}$. Se trata de un tema que en el ámbito comparado ha generado también preocupación ya que uno aspectos más problemáticos de las condenas erróneas en este tipo de procedimientos para delitos menores es que, como consecuencia que parte de ellos se aplican a figuras penales relativamente de pocas identidad, la posibilidad de controlar el error con posterioridad es muy baja ${ }^{50}$. En Europa se trata también de un tema que genera creciente preocupación y debate. Así, Gilliéron reporta que en la experiencia Suiza en procedimientos por orden penal ${ }^{51}$, ha sido frecuente encontrar casos de condenas erróneas de personas fácticamente inocentes ${ }^{52}$. Martin Killias, por su parte, apunta que la tendencia a ampliar el ámbito de aplicación de diversos tipos de procedimientos simplificados en Europa podría ser la causa de muchas condenas erróneas ${ }^{53}$.

\footnotetext{
${ }^{49}$ Recordemos que en ambos casos se imputan delitos que contemplan penas privativas de libertad en abstracto que van de 541 días a 5 años (presidio y reclusión menores en su grado medio a máximo) y, que incluso, podrían dar lugar a tramitación del caso de conformidad a un procedimiento ordinario si es que el fiscal hubiera intentando obtener una pena superior a los 540 días de privación de libertad.

${ }^{50}$ Como ya se ha visto en todo tipo de casos es difícil identificar a las condenas erróneas. Con todo, esos problemas parecen amplificarse en materia de delitos menores producto del tratamiento mucho más informal que hacen los sistemas de justician criminal respecto de ellos y el menor registro y seguimiento de los mismos, entre otras razones. Para el caso de los Estados Unidos sobre este punto puede verse NATAPOFF, Alexandra, "Misdemeanors", Southern California Law Review Vol. 85 (2012), pp. 101-163, p. 118. Sostiene la misma idea KING, John, "Beyond 'life and liberty": the evolving right to counsel", Harvard Civil RightsCivil Liberties Law Review Vol. 48 (2013), pp. 1-48, p. 22. Gross, por su parte, ha señalado que tratándose de delitos menores las condenas erróneas son casi indetectables a pesar que es probable su mucho mayor frecuencia que en delitos comunes: GROSS, Samuel, "Convicting the innocent", Annual Review of Law and Social Sciences, Vol. 4 (2008), pp. 173-199, p. 180.

${ }^{51}$ Se trata de un tipo de procedimiento sumario o simplificado parecido a nuestro procedimiento monitorio pero que incluye a simples delitos y no sólo faltas.

${ }^{52}$ GILLIÉRON, “The risk”, cit. nota $\mathrm{n}^{\circ}$ 44, pp. 242- 243. Véase también GILLIÉRON, Gladys, "Wrongful convictions in Switzerland: a problem of summary proceedings", University of Cincinnati Law Review. Vol. 80-4 (2013), pp. 1145-1165.

${ }^{53}$ KILLIAS, Martin, "Wrongful convictions in Switzerland: the experience of a continental law country", en: HUFF, Ronald; KILLIAS, Martin (Eds.), Wrongful conviction: international perspectives on miscarriages of justice, Philadelphia: Temple University Press, 2010, pp. 139-155, p. 144.
} 
Polít. crim. Vol. 10, № 19 (Julio 2015), Art. 6, pp. 159-191.

[http://www.politicacriminal.cl/Vol_10/n_19/Vol10N19A6.pdf]

Incluso en un trabajo más reciente afirma la misma idea citando nuevamente la experiencia Suiza como ejemplo ${ }^{54}$.

Una tercera causa que aparece en los casos nacionales se vincula al potencial mal comportamiento de las agencias de persecución penal. En esta línea me parece que se presentan problemas de muy diversa intensidad y gravedad. Por una parte, los casos de Pedro Lobos y Julio Robles dan claramente cuenta de un problema de mayor gravedad como es el desarrollo de una visión de túnel que explica en parte sus condenas erróneas ${ }^{55}$. Tratándose del caso de Lobos, debe recordarse que en forma paralela se llevaba a cabo otra investigación en la que se condenó como autor confeso de varios delitos idénticos a otra persona, un año antes del juicio en contra de Pedro Lobos. En el caso de Julio Robles todo el procedimiento policial de identificación de su persona como sospechoso y la manera que con posterioridad se llevan adelante los reconocimientos dan cuenta también de la existencia de una fuerte convicción policial acerca de la culpabilidad del imputado desde muy temprano y basada en una investigación de confiabilidad en extremo precaria.

Un segundo problema de comportamiento inadecuado de las agencias de persecución penal en estos casos es lo que identificaría como falta de rigor en los procesos de trabajos. El caso de Jorge Antio es un ejemplo paradigmático de esto. El señor Antio fue requerido por el Ministerio Público como autor del delito de desacato fundado en el incumplimiento de una medida cautelar decretada por tribunales de familia, medida que no se encontraba vigente y que, por lo mismo, no podía incumplirse. En un delito de ese tipo parece que la mínima información requerida para confirmar la viabilidad de la persecución penal es precisamente el antecedente de la medida que se imputa de parte de la policía se ha incumplido. Ese mínimo deber de verificación no es cumplido en el caso y lleva a que se persiga una responsabilidad penal inexistente. Algo similar puede señalarse del caso de Diego Nieto quien es condenado por un delito que ya había sido suspendido condicionalmente y también en el de Claudio Jiménez quien es condenado por porte ilegal de un arma que estaba inscrita a su nombre. Todos estos casos permiten pensar que la mecanización de ciertos procesos de trabajo, especialmente en delitos menores, puede estar llevando a los fiscales a descuidar aspectos básicos de su función como por ejemplo verificar elementos mínimos de información que permitan sustentar la condena ${ }^{56}$.

Finalmente, una cuarta causa que es posible identificar como causante de las condenas de inocentes se refiere a problemas que pudieron estar asociados a la calidad del trabajo de la

\footnotetext{
${ }^{54}$ KILLIAS, Martin, "International trends and developments: perspectives on wrongful convictions from Europe", en: REDLICH, Allison et. al, Examining Wrongful Convictions, Durham: Carolina Academic Press, 2014, pp. 321-336, p. 329.

${ }^{55}$ La visión de túnel se produce cuando los responsables de la investigación (policías o fiscales), luego de concentrarse en un sospechoso concreto, sobreestiman la evidencia disponible en su contra y de manera subconsciente descartan la posibilidad que existan otros autores o evidencia exculpatoria que surge en el resto de la investigación. MEDWED, Daniel, Prosecution Complex: America's Race to Convict and Its Impact on the Innocent. New York: New York University Press, 2012, p. 22, quien analiza este fenómeno principalmente desde el punto de vista de los fiscales.

${ }^{56}$ La investigación comparada muestra como es común en delitos menores que los fiscales relajen su función de control de la información policial y procesen estos casos sin mayor escrutinio. En el caso de Estados Unidos véase, NATAPOFF, "Misdemeanors", cit. nota n 50, pp. 125-128.
} 
DUCE, Mauricio. "La condena de inocentes en Chile: una aproximación empírica a partir de los resultados de los recursos de revisión acogidos por la Corte Suprema en el período 2007-2013".

defensa. Varios de los casos en estudio dan cuenta, con distintos niveles de magnitud, de algunos de estos problemas y cómo un trabajo inadecuado de la defensa se puede traducir en una condena de un inocente. El principal problema que se repite en las condenas de Víctor Moreno y Jorge Antio tiene que ver con el rol de la defensa en respaldar la aceptación de reconocimientos de responsabilidad de los imputados en procedimientos simplificados. En ambos casos se admite responsabilidad de una conducta que no era delito. Si llama la atención que los fiscales no hayan verificado meticulosamente que se contaba con los mínimos de información requeridos para obtener una condena, con mayor razón se esperaría que un defensor lo haga antes de recomendar a su cliente admita responsabilidad. A partir de la información disponible en las sentencias de revisión no me es posible avanzar mucho en este tema, ya que para hacer un juicio más específico se requeriría de información que no es evidente en los razonamientos de la Corte Suprema. Con todo, llama la atención que en ambos casos la representación legal de los condenados no haya impedido que se llegara a ese punto en los respectivos procesos. Esto parece ser evidencia suficiente para plantear que el problema de inadecuada asistencia legal puede ser una explicación plausible.

Junto con estos cuatro problemas que resultan consistentes con la evidencia comparada, señalé había otras potenciales causas que no tenían registro en ese ámbito y que surgen de los casos en análisis. Los casos de Rafael Tapia y Jorge Scalpello, ambos por giro doloso de cheques, muestran la existencia de algunos problemas generales de coordinación del sistema judicial muy relevantes que parecen tener una magnitud similar a la que presentan los casos de suplantación, aún cuando no parece que las responsabilidades centrales estén en manos del sistema de justicia penal. En el caso de Rafael Tapia el problema se produjo como consecuencia de un error cometido por el querellante respecto a la fecha en la que recibió el pago íntegro del cheque y sus intereses y costas que llevó al tribunal a rechazar una solicitud de sobreseimiento definitivo del caso solicitada por el condenado ya que se sostuvo el pago habría sido posterior al momento en que la sentencia se habría ejecutoriado. Con todo, luego se demostró que el pago había sido realizado en forma oportuna y que el procurador del abogado del querellante se había equivocado en las fechas por un día de diferencia. Se trata de un error grueso, pero en el que el responsable es más bien el querellante y no los jueces u otras agencias del sistema. También da cuenta de la lógica extraña que introduce al sistema penal un delito como este. Un poco distinta es la situación del Sr. Scalpello. En este caso, el problema que condujo a la condena errónea derivó de una notificación defectuosa del tribunal civil que conocía de la gestión preparatoria, ya que la notificación judicial del protesto de los cheques por parte del receptor se realizó en un domicilio que luego se acreditó no existía. Es necesario tener presente que la declaración de la nulidad de la gestión preparatoria se obtuvo con posterioridad (21 de septiembre de 2012) a la condena por el delito de giro doloso (18 de mayo de 2011). Por lo mismo, al momento de condenar al Sr. Scalpello efectivamente se cumplían con los requisitos exigidos por la ley. Este hecho parece desligar a la justicia penal de responsabilidades mayores en el error. Con todo, da cuenta de un problema serio de funcionamiento de la justicia civil en el proceso de notificación que, desde el punto de vista del condenado, hace igualmente responsable al Estado. Por otra parte, el caso también muestra problemas serios 
Polít. crim. Vol. 10, № 19 (Julio 2015), Art. 6, pp. 159-191.

[http://www.politicacriminal.cl/Vol_10/n_19/Vol10N19A6.pdf]

de funcionamiento de los sistemas de notificación en la justicia civil podría dar lugar a errores graves tanto en la propia sede civil como en materia penal.

\section{Reflexiones finales.}

A modo de reflexión final quisiera mencionar dos temas brevemente. Lo primero es que, tal como lo señalaba en la introducción, el objetivo básico de este trabajo ha sido el de producir y sistematizar información empírica que no se encuentra disponible en la literatura local de manera de conocer mejor la realidad nacional en materia de condena de inocentes. Con todo, se trata de una primera aproximación que requiere ser profundizada a futuro. Por de pronto, como he sugerido previamente, parece indispensable realizar un estudio de casos que permita conocer con mayor profundidad lo que ocurrió en cada uno de las situaciones en que se condenó a un inocente y así identificar con más precisión y claridad las causas que pueden haber influido en ese resultado. Junto con esto, los resultados de están investigación abren múltiples interrogantes que no son posibles de ser respondidas con la evidencia disponible, pero que podrían dar pie para estudios futuros. Por ejemplo, en relación a la realidad de las condenas de inocentes, ¿Qué explica la sobre representación de la Región Metropolitana y los delitos contra la propiedad? ¿La mayor gravedad en promedio de los casos se explica como consecuencia del sesgo de la muestra o ellos es reflejo de la realidad del funcionamiento del sistema?, etc. En otra dirección, también surgen preguntas de interés en materias que no son objeto central de este trabajo pero surgen de los datos, como por ejemplo, aquellas vinculadas a la dinámica de funcionamiento del recurso de revisión y lo que ocurre en los casos en que estos son desechados de plano o rechazados por la Corte Suprema. En fin, las posibilidades de temas y preguntas son múltiples. Si este trabajo genera nuevas preguntas que antes el lector no se hacía, me parece cumple entonces con su objetivo.

Un segundo punto que quisiera destacar se refiere a los hallazgos principales de la investigación. No obstante he trabajado con una base relativamente limitada de casos de errores del sistema como lo es la de los recursos de revisión, los resultados dan cuenta -en mi opinión-que no se trata de un problema menor o tan marginal como pudiera pensarse. Estamos en presencia de una cantidad no despreciable de condenas erróneas desde el año 2007, muchas de ellas adoptadas en procedimientos complejos como lo es el procedimiento ordinario, en algunos casos con sanciones graves que han llevado a personas a pasar períodos relevantes privados de libertad injustamente y en la gran mayoría de casos las condenas erróneas parecen provocarse como consecuencias de causas bastante graves. En ese contexto, no me parecería razonable que la postura de académicos y actores del sistema fuera la de no reaccionar de alguna forma frente a esta realidad. Aún cuando es cierto que los errores del sistema son en alguna medida un producto inevitable de su funcionamiento, también sabemos a esta altura - de acuerdo a lo que muestra la evidencia comparada- que es posible disminuir la probabilidad de su ocurrencia en forma significativa si se identifican y luego se transforman muchas prácticas de los actores del sistema que podrían tener incidencia relevante en su producción. El presente trabajo arroja algunas pistas acerca de situaciones problemáticas que son coincidentes con la experiencia acumulada internacionalmente en la materia, pero también da cuenta de algunas particularidades de la realidad nacional que debemos investigar con más profundidad. Espero entonces que estos 
DUCE, Mauricio. "La condena de inocentes en Chile: una aproximación empírica a partir de los resultados de los recursos de revisión acogidos por la Corte Suprema en el período 2007-2013".

resultados sean un catalizador para iniciar un largo camino de investigación y trabajo por mejorar el funcionamiento de nuestro sistema de justicia criminal en esta materia. 
Polít. crim. Vol. 10, № 19 (Julio 2015), Art. 6, pp. 159-191.

[http://www.politicacriminal.cl/Vol_10/n_19/Vol10N19A6.pdf]

\section{BIBLIOGRAFÍA}

1.- Libros, capítulos de libros y artículos:

ACKER, James et. al, "Stepping Back - Moving beyond immediate causes: criminal justice and wrongful convictions in social context", en: REDLICH, Allison et. al, Examining Wrongful Convictions, Durham: Carolina Academic Press, 2014, pp. 3-15.

CASTILLO, Ignacio, "Enjuiciando al proceso penal chileno desde el inocentrismo (algunos apuntes sobre la necesidad de tomarse en serio a los inocentes)", Polit. crim. Vol. 8, $\mathrm{n}^{\text {o }} 15$ (Julio 2013), Art. 7, pp. 249-313.

DUCE, Mauricio, “¿Debiéramos preocuparnos de la condena de inocentes en Chile? Antecedentes comparados y locales para el debate", Revista Ius et Praxis, año 19, no 1 (2013), pp. 77-138.

, "Errores del sistema y condena de inocentes: nuevos desafíos para nuestra justicia penal acusatoria", en: DECAP, Mauricio et. al, El modelo adversarial en Chile, Santiago: Legalpublishing, 2013, pp. 1-65.

, "Diez años de desarrollo de la reforma procesal penal en Chile: apuntes sobre su desarrollo, logros y objetivos", en: FUENTES, Claudio (Coord.), Diez años de reforma procesal penal en Chile. Santiago: Ediciones Universidad Diego Portales, 2011, pp. 23-75.

DURAN, Rafael, Procedimiento simplificado y monitorio en el procedimiento penal chileno, Santiago: Librotecnia, 2009.

FERNÁNDEZ, José Manuel y OLAVARRÍA, Malva, "Teoría y Práctica de la Acción de Revisión en el Nuevo Código Procesal Penal, Causal letra d) del artículo 473", Revista Ius et Praxis. Año 15, no 2 (2009), pp. 215-255.

FINDLEY, Keith, "Defining innocence”, Alabama Law Review, vol. 74.3 (2011), pp. 11571208.

"Adversarial inquisitions: rethinking the search for the truth", New York Law School Law Review, Vol. 56 (2011-2012), pp. 912-941.

FORST, Brian, "Wrongful convictions in a world of miscarriages of justice", en: HUFF, Ronald y KILLIAS, Martin (Eds.), Wrongful conviction and miscarriages of justice: causes and remedies in North American and European criminal justice systems. New York: Routledge, 2013, pp. 15-43.

GARRET, Brandon, Convicting the Innocent, Cambridge: Harvard University Press, 2011.

GILLIÉRON, Gladys, "The risk of summary proceedings, plea bargaining and penal orders in producing wrongful convictions in U.S and Europe", en: HUFF, Ronald y KILLIAS, Martin (Eds.), Wrongful conviction and miscarriages of justice: causes and remedies in North American and European criminal justice systems. New York: Routledge, 2013, pp. 237-258.

,"Wrongful convictions in Switzerland: a problem of summary proceedings", University of Cincinnati Law Review, Vol. 80-4 (2013), pp. 1145-1165.

GROSS, Samuel, "Convicting the innocent", Annual Review of Law and Social Sciences, Vol. 4 (2008), pp. 173-199, p. 180.

GROSS, Samuel; SCHAFFER, Michael, Exonerations in United States 1989-2012, 2012, 108

pp.

Disponible

en 
DUCE, Mauricio. "La condena de inocentes en Chile: una aproximación empírica a partir de los resultados de los recursos de revisión acogidos por la Corte Suprema en el período 2007-2013".

http://www.law.umich.edu/special/exoneration/Documents/exonerations_us_1989_20 12 full_report.pdf

GUADARRAMA, Cecilia, "Encarcelados por Error”, Revista Sábado, no 801 (2014), pp. 16-19.

HORVITZ, María Inés y LÓPEZ, Julián, Derecho procesal penal chileno, Tomo II, Santiago: Editorial Jurídica de Chile, 2004.

KILLIAS, Martin, "Wrongful convictions in Switzerland: the experience of a continental law country", en: HUFF, Ronald; KILLIAS, Martin (Eds.), Wrongful conviction: international perspectives on miscarriages of justice, Philadelphia: Temple University Press, 2010, pp. 139-155. "International trends and developments: perspectives on wrongful convictions from Europe", en: REDLICH, Allison et. al, Examining Wrongful Convictions, Durham, Carolina Academic Press, 2014, pp. 321-336.

KING, John, "Beyond 'life and liberty": the evolving right to counsel", Harvard Civil Rights-Civil Liberties Law Review Vol. 48 (2013), pp. 1-48.

LIBEDINSKY, Marcos (redactor), Repertorio de Legislación y Jurisprudencia Chilenas Código de Procedimiento Penal, Tomo III. Santiago: Editorial Jurídica de Chile, 1983.

MARDONES, Fernando, "Guardar silencio: El Recurso de revisión, una mezquina protección al inocente", Revista 93. № 6 (2011), pp. 45-47.

MEDWED, Daniel, Prosecution Complex: America's Race to Convict and Its Impact on the Innocent, New York: New York University Press, 2012.

NATAPOFF, Alexandra, "Misdemeanors", Southern California Law Review Vol. 85 (2012), pp. 101-163.

SIMON, Dan, In Doubt: The Psychology of the Criminal Justice Process, Cambridge: Harvard University Press, 2012.

2.- Páginas web y otros documentos electrónicos:

DEFENSORÍA PENAL PÚBLICA, Informe Estadístico Anual 2012, disponible en http://www.dpp.cl/resources/upload/files/documento/9a4c122934927b0ee2c3784299 4663e5.pdf

DEFENSORÍA PENAL PÚBLICA, Memoria Anual 2013, disponible en http://www.dpp.cl/resources/upload/files/documento/bd1eefb5a04f47e285d12fb10aa 387c6.pdf

CORPORACIÓN ADMINISTRATIVA DEL PODER JUDICIAL, Memoria Anual de la Corporación Administrativa del Poder Judicial 2007, disponible en http://www.pjud.cl/documents/10179/103881/memoria_2007.pdf/ac86f791-4ac74568-832c-cd623c7674a7

MINISTERIO PÚBLICO, Boletín Estadístico Anual 2013, disponible en http://www.fiscaliadechile.cl/Fiscalia/estadisticas/index.do

MINISTERIO DE JUSTICIA, Ord. ${ }^{\circ} 3824$ del Ministerio de Justicia de 3 de junio de 2014 en respuesta a Oficio $\mathrm{n}^{\circ} 975$ de la Cámara de Diputados (documento en formato electrónico en poder del autor 
Polít. crim. Vol. 10, № 19 (Julio 2015), Art. 6, pp. 159-191.

[http://www.politicacriminal.cl/Vol_10/n_19/Vol10N19A6.pdf]

NATIONAL REGISTRY OF EXONERATIONS,

http://www.law.umich.edu/special/exoneration/Pages/about.aspx

PROYECTO INOCENTES, http://www.proyectoinocentes.cl 
DUCE, Mauricio. "La condena de inocentes en Chile: una aproximación empírica a partir de los resultados de los recursos de revisión acogidos por la Corte Suprema en el período 2007-2013".

Anexo A

Recursos de Revisión Acogidos por la Corte Suprema 2007-2013 por años y n n rol

\begin{tabular}{|c|c|}
\hline Año & $\operatorname{Rol~n}^{0}$ \\
\hline \multirow[t]{3}{*}{2007} & $3788-2007$ \\
\hline & $5104-2007$ \\
\hline & $5546-2007$ \\
\hline \multirow[t]{6}{*}{2008} & 1494-2008 \\
\hline & $2605-2008$ \\
\hline & $3132-2008$ \\
\hline & $5049-2008$ \\
\hline & $6367-2008$ \\
\hline & $7245-2008$ \\
\hline \multirow[t]{5}{*}{2009} & $2740-2009$ \\
\hline & $3642-2009$ \\
\hline & $7627-2009$ \\
\hline & 9484-2009 \\
\hline & $9562-2009$ \\
\hline \multirow[t]{11}{*}{2010} & $167-2010$ \\
\hline & 1096-2010 \\
\hline & $3249-2010$ \\
\hline & $5498-2010$ \\
\hline & $5610-2010$ \\
\hline & $5740-2010$ \\
\hline & $7965-2010$ \\
\hline & $8046-2010$ \\
\hline & $8807-2010$ \\
\hline & $8975-2010$ \\
\hline & 9933-2010 \\
\hline \multirow[t]{5}{*}{2011} & $789-2011$ \\
\hline & $1558-2011$ \\
\hline & $2227-2011$ \\
\hline & $9502-2011$ \\
\hline & $12018-2011$ \\
\hline \multirow[t]{11}{*}{2012} & $1621-2012$ \\
\hline & $1691-2012$ \\
\hline & $1693-2012$ \\
\hline & $2030-2012$ \\
\hline & $2142-2012$ \\
\hline & $2143-2012$ \\
\hline & $4722-2012$ \\
\hline & $4835-2012$ \\
\hline & $5253-2012$ \\
\hline & $6720-2012$ \\
\hline & 8884-2012 \\
\hline \multirow[t]{3}{*}{2013} & $4308-2013$ \\
\hline & $9022-2013$ \\
\hline & $11109-2013$ \\
\hline
\end{tabular}


Polít. crim. Vol. 10, № 19 (Julio 2015), Art. 6, pp. 159-191.

[http://www.politicacriminal.cl/Vol_10/n_19/Vol10N19A6.pdf]

\section{Anexo B}

Recursos de revisión acogidos por Corte Suprema 2007-2013 organizados por año y causas

\begin{tabular}{|c|c|c|}
\hline Año & $\begin{array}{l}\text { Casos } \\
\text { Suplantación } \\
\text { Rol no }^{\circ}\end{array}$ & $\begin{array}{l}\text { Otros Casos } \\
\text { Rol no }^{\circ}\end{array}$ \\
\hline \multirow[t]{2}{*}{2007} & $3788-2007$ & 5546- 2007 \\
\hline & $5104-2007$ & \\
\hline \multirow[t]{6}{*}{2008} & 1494-2008 & \\
\hline & $2605-2008$ & \\
\hline & $3132-2008$ & \\
\hline & 5049-2008 & \\
\hline & $6367-2008$ & \\
\hline & $7245-2008$ & \\
\hline \multirow[t]{5}{*}{2009} & $2740-2009$ & \\
\hline & $3642-2009$ & \\
\hline & $7627-2009$ & \\
\hline & 9484-2009 & \\
\hline & $9562-2009$ & \\
\hline \multirow[t]{11}{*}{2010} & $167-2010$ & \\
\hline & $1096-2010$ & \\
\hline & $3249-2010$ & \\
\hline & $5498-2010$ & \\
\hline & $5610-2010$ & \\
\hline & $5740-2010$ & \\
\hline & $7965-2010$ & \\
\hline & $8046-2010$ & \\
\hline & $8807-2010$ & \\
\hline & $8975-2010$ & \\
\hline & 9933-2010 & \\
\hline \multirow[t]{3}{*}{2011} & 789-2011 & $1558-2011$ \\
\hline & $9502-2011$ & $2227-2011$ \\
\hline & & $12018-2011$ \\
\hline \multirow[t]{9}{*}{2012} & $1621-2012$ & $6720-2012$ \\
\hline & $1691-2012$ & $8884-2012$ \\
\hline & $1693-2012$ & \\
\hline & $2030-2012$ & \\
\hline & $2142-2012$ & \\
\hline & $2143-2012$ & \\
\hline & $4722-2012$ & \\
\hline & $4835-2012$ & \\
\hline & $5253-2012$ & \\
\hline \multirow[t]{2}{*}{2013} & $9022-2013$ & $4308-2013$ \\
\hline & & 11109-2013 \\
\hline
\end{tabular}

